\title{
Reactions and Surface Interactions of Saccharides in Cement Slurries
}

\author{
Benjamin J. Smith, ${ }^{\dagger}$ Lawrence R. Roberts, ${ }^{\ddagger}$ Gary P. Funkhouser, ${ }^{\S}$ Vijay Gupta, ${ }^{\prime \prime}$ and Bradley F. Chmelka* ${ }^{\dagger}$ \\ ${ }^{\dagger}$ Department of Chemical Engineering, University of California at Santa Barbara, Santa Barbara, California 93106, United States \\ ${ }^{\ddagger}$ Roberts Consulting Group, 44 Windsor Avenue, Acton, Massachusetts 01720, United States \\ ${ }^{\S}$ Halliburton, Duncan, Oklahoma 73536, United States \\ "RTI International, Research Triangle Park, North Carolina 27709, United States
}

\section{Supporting Information}

\begin{abstract}
Glucose, maltodextrin, and sucrose exhibit significant differences in their alkaline reaction properties and interactions in aluminate/silicate cement slurries that result in diverse hydration behaviors of cements. Using 1D solutionand solid-state ${ }^{13} \mathrm{C}$ nuclear magnetic resonance (NMR), the structures of these closely related saccharides are identified in aqueous cement slurry solutions and as adsorbed on inorganic oxide cement surfaces during the early stages of hydration. Solid-state $1 \mathrm{D}{ }^{29} \mathrm{Si}$ and $2 \mathrm{D}{ }^{27} \mathrm{Al}\left\{{ }^{1} \mathrm{H}\right\}$ and ${ }^{13} \mathrm{C}\left\{{ }^{1} \mathrm{H}\right\}$ NMR techniques, including the use of very high magnetic fields $(18.8 \mathrm{~T})$, allow the characterization of the hydrating silicate and aluminate surfaces, where interactions with adsorbed organic species influence hydration. These measurements establish the molecular features of the different saccharides that account

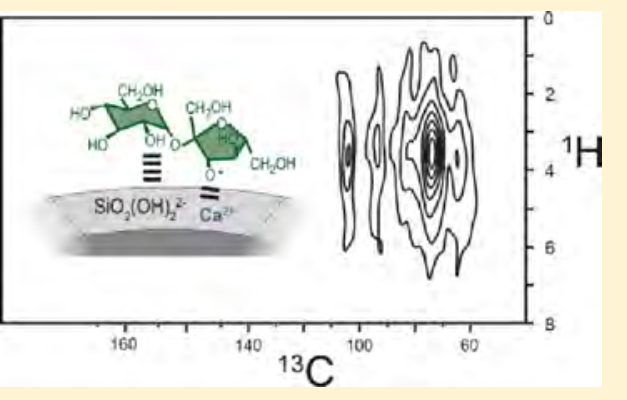
for their different adsorption behaviors in hydrating cements. Specifically, sucrose is stable in alkaline cement slurries and exhibits selective adsorption at hydrating silicate surfaces but not at aluminate surfaces in cements. In contrast, glucose degrades into linear saccharinic or other carboxylic acids that adsorb relatively weakly and nonselectively on nonhydrated and hydrated cement particle surfaces. Maltodextrin exhibits intermediate reaction and sorption properties because of its oligomeric glucosidic structure that yields linear carboxylic acids and stable ring-containing degradation products that are similar to those of the glucose degradation products and sucrose, respectively. Such different reaction and adsorption behaviors provide insight into the factors responsible for the large differences in the rates at which aluminate and silicate cement species hydrate in the presence of
\end{abstract} otherwise closely related saccharides.

\section{INTRODUCTION}

Saccharide reactions and interactions at hydrating inorganic oxide surfaces significantly influence diverse surface chemistry processes that include carbonate formation in marine organisms, biosynthesis at aluminosilicate surfaces, biofuel production over heterogeneous catalysts, corrosion inhibition, and cement hydration. ${ }^{1-7}$ The competitive adsorption of organic molecules and water at heterogeneous inorganic oxide surfaces influences reaction mechanisms, kinetics, molecular compositions and structures, and macroscopic material properties. Importantly, saccharide molecules are commonly used to alter the hydration processes and material properties of cements, such as the calcium aluminates and silicates that are widely used in synthetic structural materials. ${ }^{8}$ In particular, the hydration kinetics of hydraulic aluminate/ silicate-based cements are critical to concrete construction and oilwell cementing, in which organic additives are often used to slow (inhibit) hydration processes or alter the rheological properties of cement-water mixtures, commonly referred to as cement "slurries". Despite their enormous technological importance, much remains to be known about the physicochemical interactions of the inorganic silicate or aluminate cement components and the organic molecules during hydration. Interestingly, large variations in the hydration behaviors of cements are observed in the presence of small amounts of chemically similar sugars. These differences are hypothesized to be correlated with the molecular structures of the saccharides, their reactions in cement slurries, and their interactions at hydrating aluminate and silicate surfaces.

In the absence of chemical additives, cement hydration has been shown to involve several distinct and transient processes that are thought to influence the overall rate at which hydration occurs. ${ }^{9}$ These processes generally fall within the following categories: (1) the dissolution of molecular species from cement particle surfaces, (2) the diffusion of these species within the aqueous solution or near solid surfaces, (3) precipitation or nucleation of hydration products in solution or onto solid surfaces, and (4) the growth of disordered or crystalline hydration products. These different hydration processes may occur consecutively, concurrently, or in more complicated and coupled combinations that are influenced by the hydration kinetics of the individual and commingled aluminate and silicate chemical components. Determining the rate-controlling steps during the hydration of complicated

Received: April 13, 2012

Revised: July 5, 2012

Published: July 26, 2012 
multicomponent cements remains a significant challenge. For example, there is still much debate concerning the hydration mechanism(s) of tricalcium silicate, ${ }^{9}$ the principal component in aluminate/silicate-based cements, the rate-limiting step for which can furthermore change with time.

In the presence of additives such as saccharide molecules, cement hydration is known to be even more complicated. In particular, saccharides are used extensively to influence (usually to slow) the rate of cement hydration, although the mechanisms by which they interact on a molecular level with the heterogeneous solid components in cement slurries are not well understood. In part, this has been due to challenges associated with the molecular characterization of interactions between organic molecules and inorganic surfaces in heterogeneous fluid-particle mixtures of diverse components. Recently, using advanced techniques of solid-state $2 \mathrm{D}$ nuclear magnetic resonance (NMR) spectroscopy in combination with surface forces measurements, Smith et al. ${ }^{10}$ showed that the hydration behaviors of individual cement components, such as tricalcium aluminate and tricalcium silicate, in the presence of glucose, sucrose, or maltodextrin are correlated with the alkaline stabilities, adsorption selectivities, and binding strengths of different organic species. Important questions, however, remain regarding the interactions of different saccharide species in complicated solution-solid mixtures of aluminate and silicate components, such as those found in hydrating white Portland and gray oilwell cements.

Different hypotheses have been proposed for the mechanisms and governing processes by which organic species delay cement hydration. These can be grouped into three general categories: ${ }^{11}$ (1) the solution-phase complexation of calcium ions with organic species to reduce the availability of $\mathrm{Ca}^{2+}$ for forming calcium-silicate-hydrate $(\mathrm{C}-\mathrm{S}-\mathrm{H})$ species, (2) the adsorption of the organic species on initially nonhydrated silicate or aluminate cement components to passivate their surfaces against hydration, and (3) the adsorption of the organic species on hydrated silicate or aluminate products to restrict water diffusion to hydrating surfaces. Recent experimental evidence reviewed by Cheung et al. ${ }^{12}$ indicates that the solution complexation of $\mathrm{Ca}^{2+}$ is not likely to be a primary cause of hydration inhibition. On the basis of calorimetric, thermogravimetric, X-ray diffraction (XRD), and scanning electron microscopy (SEM) measurements, it has been hypothesized that saccharide adsorption on hydrating cement particles contributes to their relative effectiveness in slowing hydration. ${ }^{12-19}$ However, the resolution and sensitivity limitations of these methods yield little or no molecular-level information on how or where such adsorption or interactions may occur. To understand the effects of saccharides on cement hydration, it is crucial to establish their molecular interactions in solution and adsorbed on different cement species. Distinguishing such heterogeneous interactions and their differences has been challenging to establish, especially on a molecular level.

The macroscopic effects of various saccharide molecules on the rates of cement hydration have been previously reported and provide insights into the possible mechanisms of hydration inhibition. It is widely recognized that sucrose is one of the most effective hydration inhibitors in low concentrations: ${ }^{14,15,20-22}$ typical dosages of approximately $0.10 \mathrm{wt} \%$ are used in practical applications, such as oilwell cementing. By comparison, glucose is only moderately effective, requiring significantly higher concentrations (ca. $0.6 \mathrm{wt} \%$ ) to delay hydration to a similar degree. ${ }^{23}$ Polysaccharides, such as dextrins, have been studied to lesser extents, ${ }^{24}$ with hydration inhibition shown to vary with their molecular weights and structures. Recent measurements ${ }^{10}$ have established that maltodextrin exhibits intermediate efficacy at inhibiting the hydration of individual cement components, compared to sucrose and glucose. Although it has been inferred that saccharides adsorb at heterogeneous cement particle surfaces, until now, no direct measurements or identification of specific molecular interactions between adsorbed organic species and the various nonhydrated or hydrated components in cements have been reported.

Nuclear magnetic resonance (NMR) spectroscopy is a powerful tool for investigating complicated heterogeneous mixtures because the isotropic chemical shifts of NMR-active nuclei are very sensitive to their local bonding environments. One-dimensional solid-state ${ }^{29} \mathrm{Si}$ and ${ }^{27} \mathrm{Al}$ NMR spectroscopy have been used to characterize silicate and aluminate species in both nonhydrated cements and hydrating cement slurries without and with hydration inhibitors. ${ }^{10,25-32}$ Importantly, more advanced 2D NMR techniques are able to probe molecular interactions between NMR-active nuclei (e.g., ${ }^{1} \mathrm{H}$, ${ }^{13} \mathrm{C},{ }^{29} \mathrm{Si}$, and ${ }^{27} \mathrm{Al}$ ) in aluminate and silicate materials to study the binding of water molecules and organic species at inorganic oxide surfaces. ${ }^{10,32-34}$ On the basis of these studies, 2D NMR techniques are expected to yield detailed information on interactions among organic moieties, water, and silicate, and aluminate hydration products in cements, providing molecularlevel insight into bulk cement properties.

We hypothesize that the diverse effects of saccharides on cement hydration are due to their different and competitive adsorption selectivities (or those of their degradation products) among the numerous distinct species on cement particle surfaces. By using advanced solution- and solid-state NMR techniques, the transformations and interactions of mono-, di-, and polysaccharide species in alkaline cement slurry solutions and at solid cement particle surfaces can be established. Industrially important white Portland and gray oilwell cements containing the same quantities of different saccharides are examined for technologically relevant conditions, including elevated temperatures $\left(\leq 95{ }^{\circ} \mathrm{C}\right)$ and early hydration times (e.g., hours) to establish the molecular origins of hydration inhibition. The structures, concentrations, and adsorption behaviors of glucose, maltodextrin, and sucrose, including their degradation products, are quantified in aqueous cement slurries by solution-state $1 \mathrm{D}{ }^{13} \mathrm{C}$ and ${ }^{1} \mathrm{H}$ NMR measurements. Complementary solid-state $1 \mathrm{D}$ and $2 \mathrm{D}{ }^{1} \mathrm{H},{ }^{13} \mathrm{C},{ }^{29} \mathrm{Si}$, and ${ }^{27} \mathrm{Al}$ NMR methods are used to establish the structures and interactions of saccharide species at hydrating calcium silicate and aluminate surfaces in heterogeneous cement slurry mixtures. The results are correlated with macroscopic measurements of cement hydration to identify, on a molecular level, the physicochemical characteristics of the different saccharide species that account for their different hydration inhibition behaviors in cement slurries.

\section{EXPERIMENTAL SECTION}

Materials. Nonhydrated Aalborg white Portland cement (WPC, Lehigh Cement), API Class H gray oilwell cement (GOC, Lafarge), tricalcium silicate $\left(\mathrm{Ca}_{3} \mathrm{SiO}_{5}\right.$, CTLGroup), tricalcium aluminate $\left(\mathrm{Ca}_{3} \mathrm{Al}_{2} \mathrm{O}_{6}, \mathrm{CTLGroup}\right.$ ), and calcium sulfate dihydrate (gypsum, $\mathrm{CaSO}_{4} \cdot 2 \mathrm{H}_{2} \mathrm{O}$, Sigma-Aldrich) were used as received. D-Glucose and sucrose, including $99 \%{ }^{13} \mathrm{C}$-enriched species, were obtained from 
Sigma-Aldrich and used as-received. Maltodextrin (Main Street Ingredients, LaCrosse, WI, USA) had a dextrose equivalent of 40. Hydrated materials were prepared by mixing the nonhydrated materials and saccharide species with water in a high-shear blender (Fisher Scientific) at $10000 \mathrm{rpm}$ for $1 \mathrm{~min}$.

For measurements conducted on solid slurry components, cements were prepared with water-to-solids mass ratios of 0.40 for white Portland cement and gray oilwell cement and 0.50 for tricalcium silicate, which approximate those of industrial formulations. Saccharides were added in a concentration of $1.0 \%$ by weight of cement (bwoc). After being mixed, all materials were poured into polyethylene containers and hydrated at $100 \%$ relative humidity. Following hydration $\left(4\right.$ or $\left.8 \mathrm{~h}, 95{ }^{\circ} \mathrm{C}\right)$, the products were ground into a powder, immersed in liquid $\mathrm{N}_{2}$, and evacuated at 0.10 Torr and $233 \mathrm{~K}$ to remove unreacted water and quench the hydration process. ${ }^{32}$ The cement powders were kept dry thereafter. Separately, a powdered solid of neat sucrose- $\mathrm{Ca}^{2+}$ (molar ratio 1.25:1 sucrose/ $\mathrm{Ca}^{2+}$ ) was precipitated from a 1 wt \% aqueous solution of sucrose $\left(p K_{a} 12.6\right)$ in saturated $\mathrm{Ca}(\mathrm{OH})_{2}$ in a vacuum oven at $95{ }^{\circ} \mathrm{C}$. The highly alkaline ( $\mathrm{pH}$ 12.7) saturated $\mathrm{Ca}(\mathrm{OH})_{2}$ solution was filtered to remove solid particulates above $\sim 45 \mu \mathrm{m}$ prior to adding sucrose.

For measurements conducted on cement extract solutions, slurries were prepared from gray oilwell cements with a water-to-solids mass ratio of 0.40 or a $\mathrm{D}_{2} \mathrm{O}$-to-solids mass ratio of 0.50 . Following the hydration period $\left(\leq 2 \mathrm{~h}, 65^{\circ} \mathrm{C}\right)$, the cement pastes were centrifuged for $15 \mathrm{~min}$ at $3000 \mathrm{rpm}$ to separate and extract the aqueous solutions from the cement slurries (except for a small amount of residual moisture that may remain on the particles). Saccharides were added in concentrations ranging from 0.5 to $4.0 \%$ bwoc. Compared to samples prepared for the solid-state NMR measurements, shorter hydration times, lower temperatures, and higher $\mathrm{D}_{2} \mathrm{O}$-to-solids mass ratios were used to facilitate the extraction of sufficient quantities of slurry solutions from the hydrating cement slurries.

Characterization. XRD patterns were acquired on a Philips XPERT powder diffractometer using $\mathrm{Cu} \mathrm{K} \alpha$ radiation with a wavelength of $0.154 \mathrm{~nm}$. The samples were scanned at $0.9^{\circ} / \mathrm{min}$ between $2 \theta$ angles of $20-60^{\circ}$ for white Portland cement hydrated (8 h, $95{ }^{\circ} \mathrm{C}$ ) with $1 \%$ glucose bwoc (Figure 1a) and white Portland cement hydrated $\left(8 \mathrm{~h}, 95^{\circ} \mathrm{C}\right)$ with $1 \%$ sucrose bwoc (Figure $1 \mathrm{~b}$ ). Scanning electron micrographs were conducted using an FEI XL40 Sirion FEG digital electron scanning microscope at a magnification of $6500 \times$ and an electron beam voltage of $10 \mathrm{kV}$ for white Portland cement hydrated for $8 \mathrm{~h}$ at $95{ }^{\circ} \mathrm{C}$ with $1 \%$ glucose or $1 \%$ sucrose bwoc and are shown in Figure 1c,d, respectively. X-ray fluorescence analyses

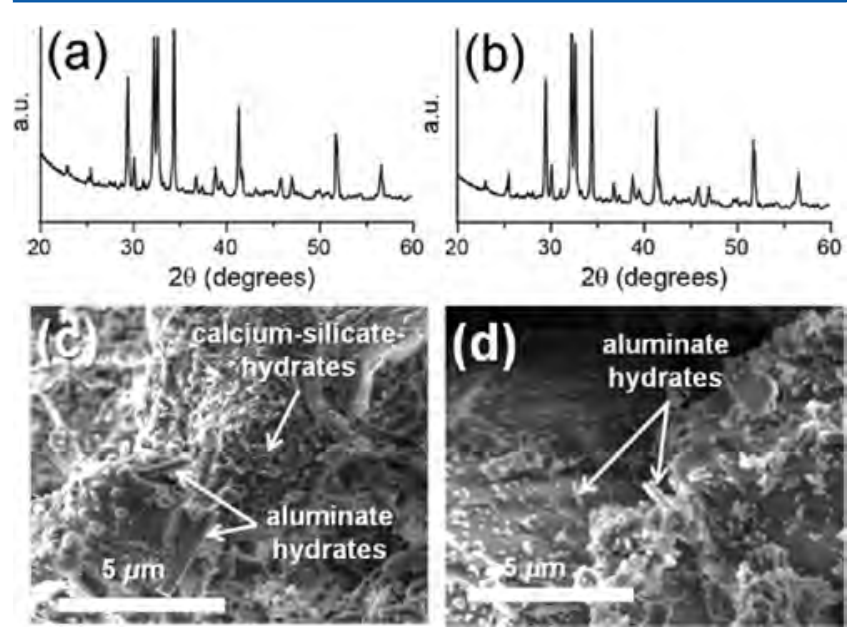

Figure 1. (a, b) Powder X-ray diffraction patterns and (c, d) scanning electron micrographs of hydrated white Portland cement $\left(8 \mathrm{~h}, 95^{\circ} \mathrm{C}\right)$ with (a, c) $1 \%$ glucose or (b, d) $1 \%$ sucrose by weight of cement (bwoc). Hydration products are labeled in the scanning electron micrograph images. were performed to determine the elemental compositions of the nonhydrated white Portland and gray oilwell cements (Supporting Information, Table S1). Rietveld analyses of X-ray diffraction patterns for the nonhydrated white Portland and gray oilwell cements were performed to identify and estimate the relative quantities of crystalline cement components (Supporting Information, Table S2).

Solution-state nuclear magnetic resonance (NMR) spectroscopy was used to characterize the molecular structures of the saccharides and to quantify these components in the hydrating cement "pore" solutions. Solution-state $1 \mathrm{D}$ single-pulse ${ }^{1} \mathrm{H}$ and attached-proton-test (APT) ${ }^{13} \mathrm{C} \mathrm{NMR}^{35}$ experiments were conducted at $25^{\circ} \mathrm{C}$ on a Bruker AVANCE-II NMR spectrometer $(11.7 \mathrm{~T})$ operating at frequencies of $500.24 \mathrm{MHz}$ for ${ }^{1} \mathrm{H}$ and $125.78 \mathrm{MHz}$ for ${ }^{13} \mathrm{C}$. The ${ }^{13} \mathrm{C}$ APT measurements were conducted using a $90^{\circ}$ pulse length of $4.0 \mu \mathrm{s}$ and result in increased ${ }^{13} \mathrm{C}$ signal sensitivity compared to that of the singlepulse ${ }^{13} \mathrm{C}$ experiment. The ${ }^{13} \mathrm{C}$ APT experiments yield positive methine $(>\mathrm{CH}-)$ and methyl $\left(-\mathrm{CH}_{3}\right)$ signals from moieties with odd numbers of covalently bonded hydrogen atoms and negative ${ }^{13} \mathrm{C}$ signals from quaternary $(>\mathrm{C}<)$ and methylene $\left(-\mathrm{CH}_{2}-\right)$ moieties with no or an even number of hydrogen atoms. Quantitative 1D single-pulse ${ }^{1} \mathrm{H}$ NMR spectra were acquired using a $90^{\circ}$ pulse length of $3 \mu \mathrm{s}$ and a recycle delay of $2 \mathrm{~s}$. For the solution-phase ${ }^{1} \mathrm{H}$ NMR measurements, $\mathrm{D}_{2} \mathrm{O}$ was used instead of $\mathrm{H}_{2} \mathrm{O}$ to prepare cement slurries to suppress the ${ }^{1} \mathrm{H}$ NMR signal from the latter in the resulting aqueous cement extract solutions. Previous studies have determined that cement hydration with $\mathrm{D}_{2} \mathrm{O}$, compared to that with $\mathrm{H}_{2} \mathrm{O}$, is slower by a factor of approximately 3 because of the kinetic isotope effects, whereby the increased mass of the deuterium atom reduces the probability that hydration will occur. ${ }^{36}$ For solution-phase ${ }^{13} \mathrm{C}$ NMR measurements, $\mathrm{H}_{2} \mathrm{O}$ was used to prepare cement slurries. The aqueous cement pore solutions, or cement extracts, were then filtered using 45 $\mu \mathrm{m}$ filter paper to remove solid particles prior to measurement.

Quantitative analyses of the relative populations of ${ }^{1} \mathrm{H}$ organic species in the cement slurry extract solutions were obtained by integrating the resolved signals, neglecting contributions from residual $\mathrm{H}_{2} \mathrm{O}$ (at $4.7 \mathrm{ppm}$ ). Normalizing the total integrated intensities from all resolved ${ }^{1} \mathrm{H}$ signals in the cement extract solution relative to the total ${ }^{1} \mathrm{H}$ signal intensity of the initial aqueous saccharide solution of known concentration (and using an identical number of ${ }^{1} \mathrm{H}$ NMR scans for each measurement) allows the total concentration of organic species in the aqueous cement extract solutions to be estimated. Analogous to measurements and analyses of gas-phase adsorption isotherms, from the total concentration of saccharide species initially present and measured relative concentrations in solution, the quantities of individual organic species adsorbed onto solid surfaces (e.g., nonhydrated or hydrated silicate or aluminate components), incorporated into hydration products, or present in interlayer regions can be established by simple component mass balances. Transient adsorption of the various organic components was monitored by plotting the quantity adsorbed (milligrams of organic component/ gram of cement) as a function of time. Adsorption behaviors of the different organic components on solid components were monitored under pseudoequilibrium conditions for a range of initial saccharide concentrations $(0.5-4.0 \%$ by weight of cement). Pseudoequilibrium adsorption isotherms were obtained by plotting the quantities of organic species adsorbed per initial mass of cement (milligrams of organic component/gram of cement) as functions of the total concentrations of organic species in the cement extract solutions. Examples of these analyses and calculations are shown for glucose in Supporting Information Figure S1.

Solid-state 1D single-pulse ${ }^{1} \mathrm{H},{ }^{29} \mathrm{Si}$, and ${ }^{27} \mathrm{Al}$ NMR experiments were performed under conditions of magic-angle spinning (MAS) to characterize the molecular compositions of hydrated white Portland and gray oilwell cements. The solid-state ${ }^{1} \mathrm{H}$ and ${ }^{29} \mathrm{Si}$ NMR spectra were acquired on a Bruker AVANCE-II NMR spectrometer (11.7 T, $25{ }^{\circ} \mathrm{C}$ ) operating at frequencies of $500.24 \mathrm{MHz}$ for ${ }^{1} \mathrm{H}$ and $99.38 \mathrm{MHz}$ for ${ }^{29} \mathrm{Si}$ and under MAS conditions of $10 \mathrm{kHz}$ using a Bruker $4 \mathrm{~mm} \mathrm{H}$ $\mathrm{X}$ double-resonance probe head and zirconia rotors with Kel-F caps. One-dimensional single-pulse ${ }^{1} \mathrm{H}$ MAS spectra were acquired using a $90^{\circ}$ pulse length of $3.4 \mu \mathrm{s}$ and a recycle delay of $2 \mathrm{~s}$. One-dimensional 
single-pulse ${ }^{29} \mathrm{Si}$ MAS spectra were acquired using a $90^{\circ}$ pulse length of $3.7 \mu$ s under conditions of proton decoupling $\left(3.4 \mu \mathrm{s} 90^{\circ}{ }^{1} \mathrm{H}\right.$ pulses) and using a recycle delay of $100 \mathrm{~s}$. The solid-state ${ }^{27} \mathrm{Al}$ NMR spectra were acquired on a Bruker AVANCE III spectrometer (18.8 T, $25{ }^{\circ} \mathrm{C}$ ), operating at frequencies of $800.43 \mathrm{MHz}$ for ${ }^{1} \mathrm{H}$ and 208.56 $\mathrm{MHz}$ for ${ }^{27} \mathrm{Al}$ and under MAS conditions of $20 \mathrm{kHz}$ using a Bruker 3.2 $\mathrm{mm}$ H-X-Y triple-resonance probe head with zirconia rotors and Kel-F caps. Experiments were conducted using a high-power $1.0 \mu$ s pulse length for ${ }^{27} \mathrm{Al}$, corresponding to a $30^{\circ}$ tip angle, under conditions of proton decoupling $\left(3.4 \mu \mathrm{s} 90^{\circ}{ }^{1} \mathrm{H}\right.$ pulses $)$ and with a recycle delay of $10 \mathrm{~s}$. The high magnetic field mitigates the effects of second-order quadrupolar interactions and yields improved signal sensitivity and resolution of the ${ }^{27} \mathrm{Al}$ species. ${ }^{37}$ The quantitative single-pulse ${ }^{27} \mathrm{Al}$ NMR measurements were calibrated as described elsewhere ${ }^{32}$ using a dense $4.7 \mathrm{mg}$ piece of $\mathrm{AlN}$ as an external reference for ${ }^{27} \mathrm{Al}$ spin counting. Quantitative solid-state single-pulse $1 \mathrm{D}^{13} \mathrm{C}$ MAS measurements were performed to characterize the molecular compositions and structures of saccharide species adsorbed on hydrated white Portland and gray oilwell cements and were calibrated using tetrakis(trimethylsilyl)silane as an external reference for ${ }^{13} \mathrm{C}$ spin counting. The ${ }^{1} \mathrm{H},{ }^{13} \mathrm{C}$, and ${ }^{29} \mathrm{Si}$ chemical shifts were referenced to tetramethylsilane using tetrakis(trimethylsilyl)silane $\left[\left(\mathrm{CH}_{3}\right)_{3} \mathrm{Si}\right]_{4} \mathrm{Si}$ as a secondary standard, and the ${ }^{27} \mathrm{Al}$ chemical shifts were referenced to an aqueous solution of $0.5 \mathrm{M}$ aluminum nitrate $\left[\mathrm{Al}\left(\mathrm{NO}_{3}\right)_{3}\right]$. Additional details regarding the protocols used for the quantitative NMR measurements and analyses are provided in the Supporting Information.

Solid-state $2 \mathrm{D}{ }^{13} \mathrm{C}\left\{{ }^{1} \mathrm{H}\right\}$ and ${ }^{27} \mathrm{Al}\left\{{ }^{1} \mathrm{H}\right\}$ HETeronuclear CORrelation (HETCOR) NMR spectra were acquired with $128 t_{1}$ increments of 24 $\mu \mathrm{s}, 1024$ transients, and a recycle delay of $1 \mathrm{~s}$ that resulted in an experimental time of $27 \mathrm{~h}$ for each $2 \mathrm{D}$ experiment. All 2D HETCOR experiments used frequency-switched Lee-Goldberg (FSLG) homonuclear decoupling during the ${ }^{1} \mathrm{H}$ evolution period and a ${ }^{1} \mathrm{H}$ radio frequency field amplitude of $70 \mathrm{kHz}$ to enhance the resolution in the ${ }^{1} \mathrm{H}$ dimension. The $2 \mathrm{D}{ }^{13} \mathrm{C}\left\{{ }^{1} \mathrm{H}\right\}$ HETCOR spectra were acquired with a $1.5 \mathrm{~ms}$ contact time and FSLG ${ }^{1} \mathrm{H}$ homonuclear decoupling. Twodimensional ${ }^{13} \mathrm{C}\left\{{ }^{1} \mathrm{H}\right\}$ HETCOR spectra of glycine were acquired separately under similar experimental conditions to reference the ${ }^{1} \mathrm{H}$ chemical shifts, calibrate the scaling factors in the indirect $\left({ }^{1} \mathrm{H}\right)$ dimension, and assess the ${ }^{1} \mathrm{H}$ resolution achievable under conditions of FSLG homonuclear decoupling. Analyses of the $2 \mathrm{D}{ }^{13} \mathrm{C}\left\{{ }^{1} \mathrm{H}\right\}$ HETCOR spectra of glycine establish ${ }^{1} \mathrm{H}$ linewidths in the indirect $\left({ }^{1} \mathrm{H}\right)$ dimensions of approximately 0.7 and $0.5 \mathrm{ppm}$ at 11.7 and $18.8 \mathrm{~T}$, respectively. The $2 \mathrm{D}^{27} \mathrm{Al}\left\{{ }^{1} \mathrm{H}\right\}$ HETCOR spectra were acquired with a $500 \mu \mathrm{s}$ contact time and a ${ }^{1} \mathrm{H}$ spin-diffusion time of $30 \mu \mathrm{s}$. The use of relatively short contact times and FSLG homonuclear decoupling limits ${ }^{1} \mathrm{H}$ spin diffusion in the $2 \mathrm{D}{ }^{13} \mathrm{C}\left\{{ }^{1} \mathrm{H}\right\}$ and ${ }^{27} \mathrm{Al}\left\{{ }^{1} \mathrm{H}\right\}$ HETCOR NMR experiments such that the correlated signal intensities observed in the $2 \mathrm{D}$ spectra are expected to arise principally from strongly dipole-dipole-coupled ${ }^{13} \mathrm{C}-{ }^{1} \mathrm{H}$ or ${ }^{27} \mathrm{Al}-{ }^{1} \mathrm{H}$ species.

\section{RESULTS AND DISCUSSION}

The adsorption behaviors of saccharide molecules and their alkaline degradation species depend strongly on their chemical structures, and these behaviors are furthermore influenced by aqueous solution compositions and conditions and the structures of the solid oxide surfaces. As a cement slurry hydrates, water in the system is generally classified by the ease of removal from the cement paste and includes ${ }^{11}$ (1) bulk-like free-pore water found in cement pores with radii larger than $100 \mathrm{~nm},(2)$ interlayer water that is held by capillary pressure and hydrogen bonding in pores smaller than $100 \mathrm{~nm}$ that permeate hydrating cement components, and (3) chemically adsorbed water that participates in the formation of surface hydration products. Similarly, organic species may also be found in the aqueous free-pore solutions or interlayer regions or bound (physically or chemically adsorbed) to solid surfaces of nonhydrated components or hydration products. In the case of saccharides such as glucose, sucrose, and maltodextrin in aqueous alkaline cement slurries, the types and distributions of organic species in the free- or interlayer-pore environments depend on the molecular compositions and structures of the sugars. Solution- and solid-state NMR spectroscopy represents a powerful combination of complementary techniques that probe the molecular structures of the saccharide species in hydrating cement systems, from which relative compositions and solution and surface structures and their interactions with different silicate and aluminate surfaces can be determined.

Saccharide Degradation in Cement Slurries. The structural changes of saccharide species in cement slurries are particularly important because they may form degradation products that interact with soluble inorganic ions or inorganic surfaces to influence hydration. During the early hydration of cement slurries, the free-pore water is typically a high-pH solution that contains a variety of inorganic ions that may form molecular complexes with or alter the structure of the saccharide. For the aqueous gray oilwell solution examined here (water/cement mass ratio $\mathrm{w} / \mathrm{c}=0.40$, hydration time $\leq 2$ $\mathrm{h})$, the $\mathrm{pH}$ was measured to be approximately 12.7 and contained soluble inorganic species that included calcium cations and oxyanions of aluminum, silicon, and iron, which form during partial dissolution of the solid cementitious components. ${ }^{21}$ Some saccharides, including glucose, have been shown to degrade in alkaline solutions, forming a variety of different degradation products with compositions and structures that depend on their initial aqueous concentrations, solution $\mathrm{pH}$, and temperature. ${ }^{38-40}$ However, sucrose has been shown to be relatively stable under similar conditions. The organic species in the aqueous free-pore solutions were investigated at the same initial concentrations of glucose, maltodextrin, or sucrose ( $\leq 1 \%$ bwoc) at elevated temperature $\left(65^{\circ} \mathrm{C}\right)$ and during early hydration periods $(\leq 2 \mathrm{~h})$ to evaluate and compare their stabilities in alkaline cement slurries under identical conditions.

The saccharides and any associated degradation species in the cement slurry extract solutions were monitored at early cement hydration times by using solution-state ${ }^{13} \mathrm{C}$ APT NMR, which revealed significant differences in their relative stabilities. These differences are clearly observed in Figure 2a,b, which compares the solution-state $1 \mathrm{D}{ }^{13} \mathrm{C}$ APT NMR spectra of a 5 wt $\%$ solution of glucose under neutral ambient conditions $(\mathrm{pH}$ $\sim 7, \sim 25{ }^{\circ} \mathrm{C}$, DI water) to a solution initially containing $1 \%$ glucose by weight of cement $(\mathrm{w} / \mathrm{c}=0.40)$ extracted from a gray oilwell cement slurry. Glucose consists of a single ring and exists as two stereoisomers in ambient aqueous solution, cyclic $\alpha$ and $\beta$ forms that give rise to distinct ${ }^{13} \mathrm{C}$ signals at 96 and 92 $\mathrm{ppm}$, respectively, that are resolved in Figure $2 \mathrm{a}$. The isotropic chemical shifts of the distinct ${ }^{13} \mathrm{C}$ atoms in the glucose molecule have been previously assigned ${ }^{41}$ and are resolved and labeled as shown in Figure 2a. Under neutral ambient solution conditions, glucose does not degrade or transform to form other species, within the sensitivity limits of the ${ }^{13} \mathrm{C}$ measurement $(<0.1$ wt \%).

In contrast, during the early hydration of gray oilwell cement, glucose molecules undergo considerable chemical transformations to form a mixture of carboxylic acids. In homogeneous alkaline solutions ( $<2 \mathrm{wt} \%$ glucose, $\left.100{ }^{\circ} \mathrm{C}\right)$, the primary lowmolecular-weight products $\left(\leq \mathrm{C}_{4}\right)$ of alkaline glucose degradation have been shown to be carboxylic acids, including acetic, lactic, formic, and glyceric acids. ${ }^{38,39}$ Higher-molecular-weight degradation products $\left(\geq C_{5}\right)$ include various saccharinic acids 

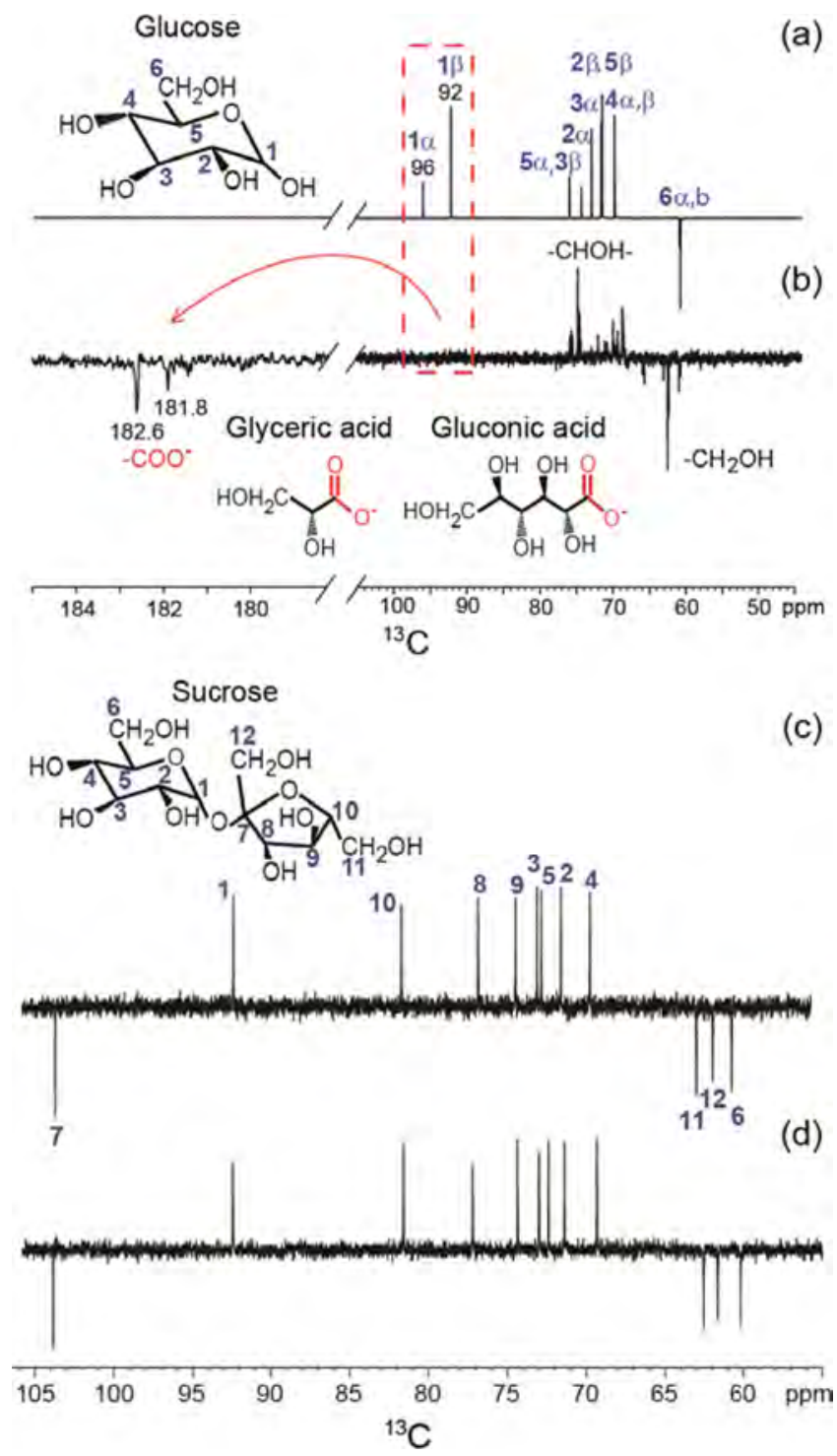

Figure 2. Solution-state ${ }^{13} \mathrm{C}$ APT NMR spectra acquired at $25{ }^{\circ} \mathrm{C}$ for (a) a 5 wt \% glucose solution at $\mathrm{pH} \mathrm{7;} \mathrm{(b)} \mathrm{an} \mathrm{aqueous} \mathrm{solution}$ extracted from a gray oilwell cement slurry hydrated for $2 \mathrm{~h}$ at $65^{\circ} \mathrm{C}$ that initially contained $1 \%$ glucose bwoc; (c) a 5 wt \% sucrose solution at $\mathrm{pH} \mathrm{7}$; and (d) an aqueous solution extracted from a gray oilwell cement slurry after $2 \mathrm{~h}$ at $65{ }^{\circ} \mathrm{C}$ and initially containing $1 \%$ sucrose bwoc. Schematic structures of glucose and sucrose are shown in a and c with their distinct ${ }^{13} \mathrm{C}$ sites labeled, along with likely glucose degradation products in $\mathrm{b}$.

such as glucosaccharinic, glucometasaccharinic, and glucoisosaccharinic acid, which can be present in appreciable quantities ( $>25$ wt $\%$ of total organic species). Similar species are observed by comparing the ${ }^{13} \mathrm{C}$ APT NMR spectra in Figure $2 \mathrm{a}, \mathrm{b}$, the latter of which was acquired for the aqueous solution extract isolated from an oilwell cement slurry $(\mathrm{w} / \mathrm{c}=0.40,1 \%$ glucose bwoc) hydrated for $2 \mathrm{~h}$ at $65^{\circ} \mathrm{C}$ and $\mathrm{pH}$ 12.7. The two spectra show notable differences in the numbers and positions of the ${ }^{13} \mathrm{C}$ signals. These include ${ }^{13} \mathrm{C}$ signals at 181.8 and 182.6 $\mathrm{ppm}$ in a region of the spectrum that is characteristic of carboxylic acids. On the basis of the expected ring-opening behavior of glucose molecules under alkaline conditions, ${ }^{38}$ these signals and others in the range of $70-80 \mathrm{ppm}$ from $-\mathrm{CHOH}$ moieties are assigned to glyceric acid and gluconic acid, respectively (Figure $2 \mathrm{~b}$, insets), consistent with separate solution-state ${ }^{13} \mathrm{C}$ APT NMR measurements (Supporting Information, Figure S2a,b). Gluconic acid is not a common glucose degradation product in alkaline solutions, although it has been observed in the presence of certain metal cations; ${ }^{42,43}$ we hypothesize that similar metal species (e.g., iron oxides and hydroxides) in solution or at particle surfaces catalyze its formation in oilwell cement slurries. The ${ }^{13} \mathrm{C}$ APT NMR spectrum (Figure $2 \mathrm{~b}$ ) of the aqueous cement extract originally containing $1 \%$ glucose bwoc shows no ${ }^{13} \mathrm{C}$ signals from $\mathrm{C} 1 \alpha$ (96 ppm) or $\mathrm{C} 1 \beta(92 \mathrm{ppm})$ moieties, establishing that cyclic glucose molecules are no longer present in the cement solution (within the sensitivity of the NMR measurements.) Weak ${ }^{13} \mathrm{C}$ signals arise from other degradation species that are present in relatively small quantities. Previous studies have established the mechanisms of alkaline glucose degradation, ${ }^{38,39}$ which can result in complicated mixtures of more than 50 compounds and are influenced by the glucose concentration, $\mathrm{pH}$, temperature, cation species, and surface interactions. These ${ }^{13} \mathrm{C}$ APT NMR analyses thus demonstrate that at early cement hydration times and elevated temperatures glucose reacts under alkaline conditions to form glyceric and gluconic acids, which remain in the aqueous cement solution, whereas other chemical species are either present in small quantities or are adsorbed on solid surfaces.

In contrast to glucose under otherwise identical conditions, sucrose does not degrade to any significant extent in aqueous (alkaline) gray oilwell cement solutions. Sucrose is a disaccharide composed of glucose and fructose monomer units that give rise to 12 distinct ${ }^{13} \mathrm{C}$ signals under ambient solution conditions that are well resolved and assigned in the ${ }^{13} \mathrm{C}$ APT NMR spectrum in Figure $2 c .{ }^{44}$ Importantly, the same ${ }^{13} \mathrm{C}$ signals and no others are observed in the ${ }^{13} \mathrm{C}$ APT NMR spectrum of the aqueous alkaline extract from a gray oilwell cement slurry that originally contained $1 \%$ sucrose bwoc (Figure 2d). This establishes that within the sensitivity limits of the measurement no degradation products of the disaccharide sucrose are detected in solution. Small differences are observed when comparing the isotropic ${ }^{13} \mathrm{C}$ chemical shifts of sucrose in the neutral aqueous solution (Figure $2 \mathrm{c}$ ) and in the aqueous cement extract (Figure 2d). These changes result from the different alkalinities of the two aqueous solutions $(\mathrm{pH} \sim 7$ vs $\mathrm{pH} \sim 12.7)$ and are consistent with previous solution-state ${ }^{13} \mathrm{C}$ NMR measurements of similar aqueous solutions and the deprotonation of the $\mathrm{C} 8$ moiety under alkaline conditions $\left(\mathrm{p} K_{\mathrm{a}} \sim 12.6\right)$. As such, these results establish that at early cement hydration times and elevated temperatures sucrose remains stable, although likely partially deprotonated, in aqueous gray oilwell cement solutions.

Compared to monosaccharides, the alkaline degradation of polysaccharides, such as maltodextrin, is generally even more complicated and leads to a variety of oligosaccharides, monosaccharides, and lower-molecular-weight carboxylic acids. ${ }^{45,46}$ Maltodextrin is an oligomeric saccharide that consists of glucose units that are connected by bridging oxygen atoms. Solution-state $1 \mathrm{D}{ }^{13} \mathrm{C}$ APT NMR measurements of maltodextrin under ambient solution conditions (Supporting Information, Figure S3a) and an aqueous cement extract originally containing 1\% maltodextrin bwoc (Supporting Information, Figure S3b) establish that maltodextrin degrades in cement slurries and that principally monosaccharides or lowermolecular-weight species remain in the aqueous cement solution. As opposed to glucose, only one primary degradation species, possibly glucoisosaccharinic acid, appears to be present 
in the aqueous cement extract solution after $2 \mathrm{~h}$ at $65^{\circ} \mathrm{C}$, with other maltodextrin degradation products being present in low concentrations or adsorbed on solid particle surfaces.

The foregoing analyses establish that unlike glucose and maltodextrin, sucrose molecules do not degrade in alkaline cement solutions and that different degradation products are observed in gray oilwell cement extracts initially containing glucose or maltodextrin. The results are consistent with previous studies ${ }^{13,14}$ that have shown sucrose to be stable in alkaline solutions (a nonreducing sugar), whereas glucose and other higher-molecular-weight aldoses, such as maltodextrin, degrade (reducing sugars). Importantly, these solution-phase NMR measurements detect organic species only in the aqueous cement extracts, and as solid-state NMR measurements will show below, additional degradation products may be adsorbed onto cement particle surfaces. The differences in the molecular structures of the different saccharides lead to varied reaction products in alkaline cement slurries that influence interactions at solid oxide surfaces and lead to large variations in the rates at which cements hydrate.

Saccharide Adsorption in Cement Slurries. The quantities and site selectivities of saccharides or their alkaline degradation species adsorbed onto cement particle surfaces are crucial to establishing their relative efficacies in inhibiting hydration in cements. Here, we determine the quantities of glucose, sucrose, maltodextrin, and their degradation species adsorbed on gray oilwell cement particles that are hypothesized to account for the different hydration behaviors of cements. The relative amounts of organic species in the interlayer water and adsorbed onto solid particle surfaces can be quantitatively measured by solution-state $1 \mathrm{D}$ single-pulse ${ }^{1} \mathrm{H}$ NMR for different initial saccharide concentrations and hydration times. Aqueous cement solution extracts were obtained as above, using initial saccharide concentrations ranging from 0.5 to $4.0 \%$ bwoc $\left(\mathrm{D}_{2} \mathrm{O} /\right.$ cement $\left.=0.50\right)$ and hydrated with $\mathrm{D}_{2} \mathrm{O}$ between 0 and $2 \mathrm{~h}$ at $65^{\circ} \mathrm{C} .{ }^{47}$ Transient adsorption of the various organic components was monitored by plotting the quantity adsorbed (milligrams of organic component/gram of cement) as a function of hydration time to investigate their adsorption behaviors.

At early hydration times, the quantities of saccharides and their alkaline degradation species adsorbed on solid cement components vary considerably and appear to be uncorrelated with their different efficacies for inhibiting cement hydration. Figure 3a shows the overall quantity of saccharide species or their degradation products (milligrams of organic component/ gram of cement) that are adsorbed onto cement particle surfaces (nonhydrated or hydrated) as a function of time for $1.25 \%$ glucose, maltodextrin, or sucrose bwoc in gray oilwell cement slurries $\left(\mathrm{D}_{2} \mathrm{O} /\right.$ cement $\left.=0.50,65{ }^{\circ} \mathrm{C}\right)$ during the early stages of hydration $(<2 \mathrm{~h})$. The adsorption uptakes of the various saccharides all reflect rapid rates of initial adsorption $(<10 \mathrm{~min})$, followed by a gradual decrease in adsorption rates (10-40 $\mathrm{min})$ until the quantity of adsorbed species no longer changed significantly (>40 min). The initial rates of adsorption appear to be similar for all saccharide species, with increased adsorption observed for glucose and maltodextrin at longer times ( $>5 \mathrm{~min}$ ) compared to that for sucrose. Following hydration for approximately $1 \mathrm{~h}$, the quantities of adsorbed species no longer changed, reflecting pseudoequilibrium conditions in which the adsorbed organic species were in instantaneous equilibrium with their respective solutions, although the cement slurries continued to hydrate slowly. It
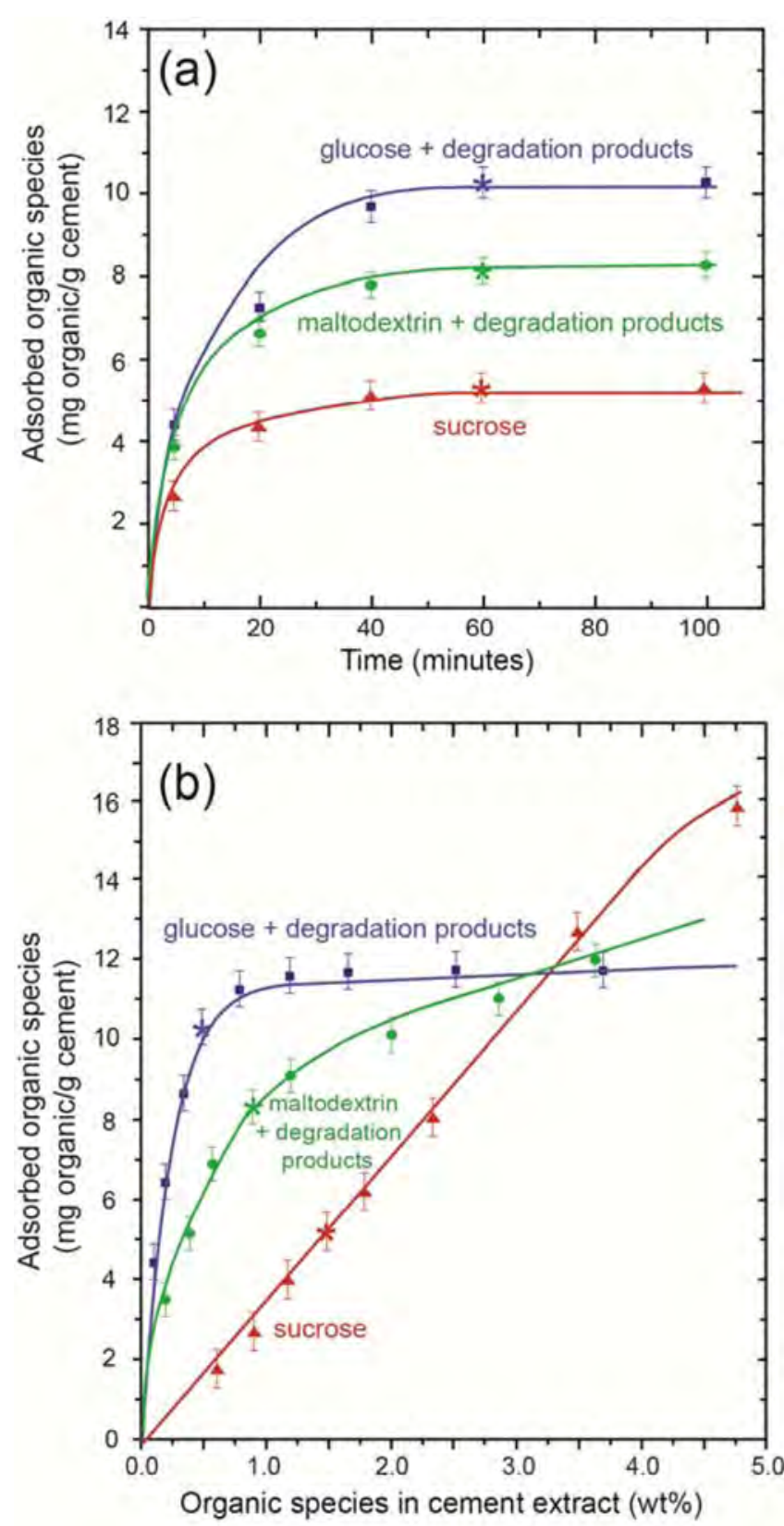

Figure 3. (a) Plot of transient adsorption of glucose (blue squares), maltodextrin (green circles), sucrose (red triangles), and/or their degradation products on gray oilwell cement from alkaline $\mathrm{D}_{2} \mathrm{O}$ solutions that initially contained $1.25 \%$ saccharide bwoc (corresponding to $12.5 \mathrm{mg}$ of saccharide/g of cement and $\mathrm{D}_{2} \mathrm{O} /$ cement $=0.50$ ) at $\mathrm{pH} 12.7$ and $65{ }^{\circ} \mathrm{C}$. (b) Plot of pseudoequilibrium adsorption of glucose (blue squares), maltodextrin (green circles), sucrose (red triangles), and/or their degradation products on gray oilwell cement from slurries hydrated with $\mathrm{D}_{2} \mathrm{O}\left(\mathrm{D}_{2} \mathrm{O} /\right.$ cement $\left.=0.50, \mathrm{pH} 12.7\right)$ for 1 $\mathrm{h}$ at $65{ }^{\circ} \mathrm{C}$. Total quantities of organic species adsorbed on cement solids are plotted as functions of the concentrations of organic species in the cement extract solutions. The asterisks indicate identical data points in $\mathrm{a}$ and $\mathrm{b}$. Solid lines are shown to guide the eye.

is noteworthy that, under such pseudoequilibrium conditions, the quantities of adsorbed species were observed to be 10.2, 8.2, and $5.1 \mathrm{mg} / \mathrm{g}$ for glucose, maltodextrin, and sucrose, respectively (Figure 3a). The adsorption uptakes of these different saccharides are likely influenced by the rapid hydration of tetracalcium aluminoferrite, which is expected to form small 
quantities of aluminate hydration products (e.g., ettringite, calcium aluminate monosulfate, and calcium aluminate hydrates). In addition, the alkaline degradation of glucose and maltodextrin has a strong influence on the adsorption uptakes of corresponding organic species onto cement particle surfaces (as shown below). Overall, these measurements establish that the quantities of the different adsorbed saccharide species or their degradation products are not directly correlated with their tendencies to inhibit the hydration of cement.

By measuring the quantities of saccharides or their degradation species adsorbed under otherwise identical alkaline solution conditions at $65{ }^{\circ} \mathrm{C}$ on gray oilwell cement, their respective pseudoequilibrium adsorption isotherms can be measured and compared. Whereas adsorption isotherms correspond inherently to fluid-solid systems at equilibrium, such conditions are not strictly achievable in hydrating alkaline cement slurries. Nevertheless, as discussed above, the quantities of adsorbed organic species do not change significantly following hydration for approximately $1 \mathrm{~h}$ (at $65^{\circ} \mathrm{C}$ ), and pseudoequilibrium adsorption is achieved. Under such conditions, quantitative measurements of organic molecule adsorption on solid cement particles can yield insights into solute-surface interactions. ${ }^{48-50}$ For example, Figure $3 \mathrm{~b}$ shows the quantities of different adsorbed saccharides and their associated degradation species plotted as functions of their corresponding total organic concentrations in cement extract solution for a range of initial saccharide concentrations (0.5$4.0 \%$ bwoc) in gray oilwell cement slurries under otherwise identical pseudoequilibrium conditions $\left(\mathrm{D}_{2} \mathrm{O} /\right.$ cement $=0.50$, $65{ }^{\circ} \mathrm{C}$, hydrated for $1 \mathrm{~h}$ ). The quantities of adsorbed glucose (or its associated alkaline degradation products) are observed to increase until reaching a plateau at higher concentrations of glucose (>1.0 wt \%). Despite the heterogeneous nature of the cement mixture, this is consistent with the Langmuir-like adsorption of the soluble organic species onto cement particle surfaces, where the observed plateau indicates that as the surfaces become saturated further adsorption is disfavored. Maltodextrin exhibits similar adsorption behavior, although compared to glucose the overall quantity of adsorbed organic species is reduced and the adsorption plateau is not as welldefined. In contrast, the quantity of adsorbed sucrose in the cement appears to vary linearly with its solution concentration; the absence of a well-defined plateau indicates that sucrose adsorbs in multiple layers at cement surfaces. Such multilayer adsorption of sucrose is consistent with recent surface forces measurements ${ }^{10}$ that quantified multilayer sucrose adsorption on aluminosilicate mica surfaces from similar alkaline solutions $\left(\mathrm{pH}=12.7,25^{\circ} \mathrm{C}\right)$ and establishes that sucrose adsorbs differently at cement surfaces than does glucose or maltodextrin. Compared to glucose and maltodextrin for the same initial solution concentrations, a smaller quantity of sucrose is adsorbed onto the cement surfaces. Nevertheless, sucrose is significantly more effective than glucose or maltodextrin at inhibiting cement hydration.

The preceding analyses quantify the overall concentrations of different saccharides in cement slurry solutions, compared to the quantities adsorbed on cement surfaces or incorporated into hydration products. As such, they probe nonspecific adsorption but do not probe or establish the specific silicate or aluminate cement components onto which the organic species adsorb and that are important for understanding their different influences on cement hydration. Solution-state ${ }^{1} \mathrm{H}$ and ${ }^{13} \mathrm{C}$ NMR analyses establish the identities and overall concen- trations of aqueous phase and adsorbed organic species in cement slurries. Interestingly, the overall quantities (i.e, nonspecific adsorption) of the adsorbed saccharides or their degradation species are not directly correlated with the efficacies of the saccharides for inhibiting cement hydration. This indicates that factors other than the overall masses of the adsorbed organic components (e.g., adsorption selectivities) must account for their diverse effects on cement hydration. These influences can be probed in detail by using solid-state NMR to measure, on a molecular level, the compositions, structures, and interactions of the saccharides, their degradation species, and water with the different solid silicate and aluminate components of which cement is composed.

Saccharide-Mediated Hydration of White Portland Cement. Tricalcium Silicate and Aluminate Hydration. The different cement hydration rates in the presence of glucose, maltodextrin, and sucrose are strongly influenced by interactions between the saccharide molecules or their alkaline degradation products and the silicate and aluminate species at hydrating cement particle surfaces. The extent of white Portland cement hydration and the quantities of different silicate and aluminate hydration products can be established by combined solid-state single-pulse $1 \mathrm{D}{ }^{29} \mathrm{Si}$ and ${ }^{27} \mathrm{Al}$ MAS NMR measurements (Supporting Information, Figure S4). For example, by comparing the relative integrated ${ }^{29} \mathrm{Si}$ NMR signal intensities associated with nonhydrated $Q^{0}$ species found in diand tricalcium silicate and the $Q^{1}$ and $Q^{2}$ moieties associated with $\mathrm{C}-\mathrm{S}-\mathrm{H}$, the extent of silicate hydration can be determined. ${ }^{10}$ Such analyses of the solid-state $1 \mathrm{D}$ single-pulse ${ }^{29}$ Si MAS spectra for white Portland cement hydrated ( 4 h, 95 ${ }^{\circ} \mathrm{C}$ ) with $1 \%$ glucose or sucrose bwoc (Supporting Information, Figure S4a,b) establish that under these conditions no significant quantities $\left(<1\right.$ wt \%) of $Q^{1}(-79 \mathrm{ppm})$ or $Q^{2}$ $(<-82 \mathrm{ppm})$ species have formed. For the purposes of later discussion, $Q^{0}{ }^{29} \mathrm{Si}$ species will be considered to be nonhydrated (including those with hydroxyl ligands), whereas cross-linked $Q^{1}$ and $Q^{2}{ }^{29} \mathrm{Si}$ moieties (the principal products of silicate hydration during cement setting) will be referred to as hydrated. These results are consistent with the early hydration kinetics of tricalcium silicate in the presence of saccharides, where organic species have been shown to delay the onset of $\mathrm{C}-\mathrm{S}-\mathrm{H}$ formation at both ambient and elevated temperatures. ${ }^{10,15}$ Thus, after hydration for $4 \mathrm{~h}$ at $95^{\circ} \mathrm{C}$, the addition of $1 \%$ glucose or sucrose bwoc almost completely inhibits the formation of calcium silicate hydrates in white Portland cement.

The early hydration of tricalcium silicate is generally divided into three stages that are characterized by different rates of hydration. Stage 1 is a brief period (ca. minutes) of rapid dissolution that begins upon wetting of the $\mathrm{C}_{3} \mathrm{~S}$ particle surfaces and results in the formation of etch pits (that are thought to initiate at $\mathrm{C}_{3} \mathrm{~S}$ surface dislocations $)^{51}$ and a rapid increase in the concentration of dissolved ions (e.g., $\mathrm{H}_{2} \mathrm{SiO}_{4}{ }^{2-}, \mathrm{Ca}^{2+}$ ) in solution. Subsequently, during stage 2 , commonly referred to as the induction period, the rate of hydration slows significantly, although the mechanism responsible for reduced hydration is still under debate. ${ }^{51,52}$ Until recently, it has been widely hypothesized that a continuous, metastable passivation layer of hydration products forms on the $\mathrm{C}_{3} \mathrm{~S}$ particle surfaces to inhibit further hydration. ${ }^{52-55}$ More recently, it has been suggested that the induction period is associated predominantly with $\mathrm{C}_{3} \mathrm{~S}$ dissolution from etch-pit steps, which is influenced by the degree of undersaturation of the solution with respect to $\mathrm{C}_{3} \mathrm{~S}^{51}$ During the induction period, the solution becomes locally 
saturated with respect to $\mathrm{C}-\mathrm{S}-\mathrm{H}$ and the hydrates likely begin to precipitate onto particle surfaces, processes that are thought not to be directly responsible for the induction period itself. At the end of the induction period, hydration accelerates and calcium silicate hydrates form rapidly, consuming ions in solution and promoting further $\mathrm{C}_{3} \mathrm{~S}$ dissolution. Previous studies ${ }^{15}$ have suggested that saccharides inhibit hydration by extending the induction period and delaying the onset of rapid $\mathrm{C}-\mathrm{S}-\mathrm{H}$ formation at ambient temperatures. Importantly, the 1D single-pulse ${ }^{29} \mathrm{Si}$ MAS spectra of white Portland cement hydrated under these conditions $\left(4 \mathrm{~h}, 95^{\circ} \mathrm{C}\right)$ establish that $1 \%$ glucose or sucrose bwoc extends the induction period of tricalcium silicate such that no measurable quantities of $(<1 \mathrm{wt}$ \%) $\mathrm{C}-\mathrm{S}-\mathrm{H}$ products are formed.

Similarly, the quantities of different aluminate hydration products in white Portland cement can be established by solidstate $1 \mathrm{D}{ }^{27} \mathrm{Al}$ MAS NMR measurements conducted at very high magnetic fields to determine the influences of the different saccharides on the hydration of aluminate species. For example, the single-pulse $1 \mathrm{D}^{27} \mathrm{Al}$ MAS spectra of white Portland cement hydrated $\left(4 \mathrm{~h}, 95^{\circ} \mathrm{C}\right)$ in the presence of $1 \%$ glucose or sucrose bwoc (Supporting Information, Figure S4c,d) exhibit signals from ${ }^{27} \mathrm{Al}^{\mathrm{IV}}$ moieties in nonhydrated aluminate components and ${ }^{27} \mathrm{Al}^{\mathrm{VI}}$ species in their resulting hydration products. Nonhydrated tricalcium aluminate is associated with broad signal intensity in the range of 55-75 ppm attributed to ${ }^{27} \mathrm{Al}^{\mathrm{IV}}$ species; ${ }^{10,32}$ the absence of such a signal in the ${ }^{27} \mathrm{Al}$ NMR spectra of white Portland cement hydrated with $1 \%$ glucose and sucrose bwoc (Supporting Information, Figure S4c,d) establishes that tricalcium aluminate is completely hydrated. The two ${ }^{27} \mathrm{Al}$ signals at 79 and $86 \mathrm{ppm}$ correspond to four-coordinate $\mathrm{Al}^{\mathrm{IV}}$ moieties within predominantly dicalcium silicate and tricalcium silicate phases, respectively. ${ }^{32}$ Notably, the solid-state single-pulse ${ }^{27} \mathrm{Al}$ MAS spectra establish that similar quantities of NMR-visible ${ }^{27} \mathrm{Al}^{\mathrm{VI}}$ hydration products are formed in the presence of both glucose and sucrose. Consequently, under these conditions the extents of hydration for both silicate and aluminate species in white Portland cement are similar in the presence of glucose or sucrose.

These experimental hydration conditions $\left(4 \mathrm{~h}, 95{ }^{\circ} \mathrm{C}, 1 \%\right.$ glucose or sucrose bwoc) provide a snapshot of white Portland cement hydration in the presence of the different saccharides: negligible $\mathrm{C}_{3} \mathrm{~S}$ hydration and complete $\mathrm{C}_{3} \mathrm{~A}$ hydration. These results run counter, at least for short hydration times, to the long-established observation that sucrose inhibits cement hydration more effectively than glucose. However, their respective longer-term transient behaviors are significantly different. Quantitative solid-state $1 \mathrm{D}$ single-pulse ${ }^{29} \mathrm{Si}$ MAS measurements (Supporting Information, Figure S5) of white Portland cement hydrated for longer periods of time $(8 \mathrm{~h})$ under otherwise identical conditions establish that substantially different quantities of calcium silicate hydrates are formed in the presence of glucose compared to when sucrose is used. Specifically, whereas for $1 \%$ glucose bwoc the extent of silicate hydration is $17 \%$, no measurable quantities $(<1 \%)$ of calcium silicate hydrates are detected in the presence of sucrose. These results show that sucrose delays the onset of $\mathrm{C}-\mathrm{S}-\mathrm{H}$ formation for longer periods of time than glucose and establish that overall hydration inhibition (i.e., the hydration of both silicate and aluminate species) in white Portland cement is correlated with the onset of formation of calcium silicate hydrates. Importantly, this suggests that the widely varying influences of different saccharides on the hydration of cements originate from their distinct adsorption behaviors on heterogeneous cement species. In particular, the adsorption characteristics of different organic species on tricalcium silicate surfaces are hypothesized to account for the significantly different extents of hydration that are observed after longer periods (e.g., $8 \mathrm{~h}$ ).

Glucose Interactions in White Portland Cement. The molecular origins of the different cement hydration rates in the presence of glucose, maltodextrin, or sucrose are related to the structures of the different saccharide molecules or their degradation species, which strongly influence their adsorption behaviors at hydrating silicate and aluminate surfaces. The combination of solid-state $2 \mathrm{D}{ }^{27} \mathrm{Al}\left\{{ }^{1} \mathrm{H}\right\}$ and ${ }^{13} \mathrm{C}\left\{{ }^{1} \mathrm{H}\right\}$ HETCOR NMR measurements allows molecular interactions between distinct organic moieties of the different saccharides and aluminate surface species to be unambiguously identified. The molecular compositions and surface structures of hydrating white Portland cement can be probed in detail by $2 \mathrm{D}{ }^{27} \mathrm{Al}\left\{{ }^{1} \mathrm{H}\right\}$ HETCOR NMR measurements conducted at $18.8 \mathrm{~T}$, which are sensitive to dipole-dipole couplings between ${ }^{27} \mathrm{Al}$ and ${ }^{1} \mathrm{H}$ nuclei and their respective chemical shifts. Such measurements probe the interactions between ${ }^{27} \mathrm{Al}$ and ${ }^{1} \mathrm{H}$ species, including water, at particle surfaces. For example, Figure 4a shows the 2D ${ }^{27} \mathrm{Al}\left\{{ }^{1} \mathrm{H}\right\}$ HETCOR spectrum of white Portland cement hydrated $\left(4 \mathrm{~h}, 95{ }^{\circ} \mathrm{C}\right)$ in the presence of $1 \%$ glucose bwoc (99\% ${ }^{13} \mathrm{C}$-labeled). In the accompanying $1 \mathrm{D}$ single-pulse ${ }^{27} \mathrm{Al}$ MAS spectrum (Figure 4a, top) of hydrated tricalcium aluminate, a broad, featureless ${ }^{27} \mathrm{Al}$ signal is observed at 9 ppm that is associated with six-coordinate aluminate hydrate species. The $2 \mathrm{D}{ }^{27} \mathrm{Al}\left\{{ }^{1} \mathrm{H}\right\}$ HETCOR spectrum provides enhanced resolution in which intensity correlations from multiple ${ }^{27} \mathrm{Al}$ signals are partially resolved. These are visible in the projected spectrum along the ${ }^{27} \mathrm{Al}$ axis, in which partially overlapping signals can nevertheless be distinguished at 9.0 ppm from calcium aluminate monosulfate $\left(\mathrm{Ca}_{4} \mathrm{Al}_{2} \mathrm{O}_{6}\left(\mathrm{SO}_{4}\right) \cdot 12 \mathrm{H}_{2} \mathrm{O}\right)$, at $7.5 \mathrm{ppm}$ from tetracalcium aluminate hydrate $\left(\mathrm{Ca}_{4} \mathrm{Al}_{2} \mathrm{O}_{7} \cdot 13 \mathrm{H}_{2} \mathrm{O}\right)$, and at $6.5 \mathrm{ppm}$ from what is often referred ${ }^{31}$ to as the third aluminate hydrate (TAH). These ${ }^{27} \mathrm{Al}$ peak assignments are based on previous ${ }^{27} \mathrm{Al}$ NMR studies ${ }^{31,32,56-58}$ and establish that a mixture of aluminate hydrates, including both calcium aluminates and calcium aluminate sulfates, are formed under the hydration conditions examined. The absence of significant ${ }^{27} \mathrm{Al}$ signal intensity at $10 \mathrm{ppm}$ from ettringite, a common aluminate hydrate formed during the hydration of cement under ambient conditions (e.g., $25^{\circ} \mathrm{C}$ ), is consistent with previous in situ synchrotron X-ray powder diffraction studies ${ }^{59}$ that showed ettringite formation to be severely inhibited at elevated temperatures $\left(>70{ }^{\circ} \mathrm{C}\right)$. Strong $2 \mathrm{D}$ intensity correlations are observed between these ${ }^{27} \mathrm{Al}^{\mathrm{VI}}$ signals centered at 9.0 and 7.5 ppm and the ${ }^{1} \mathrm{H}$ signals at 1.1 and $1.7 \mathrm{ppm}$, which are thus assignable to different $-\mathrm{AlOH}$ moieties associated with sixcoordinate ${ }^{27} \mathrm{Al}^{\mathrm{VI}}$ species in monosulfate and tetracalcium aluminate hydrate, respectively. Although approaching the ${ }^{1} \mathrm{H}$ resolution limits of the $2 \mathrm{D}{ }^{27} \mathrm{Al}\left\{{ }^{1} \mathrm{H}\right\}$ HETCOR spectrum, this indicates that the ${ }^{1} \mathrm{H}$ and ${ }^{27} \mathrm{Al}$ signals associated with these two related aluminate hydrates can be resolved by correlating their respective frequencies in the $2 \mathrm{D}$ maps. Two weaker-intensity correlations are observed between the ${ }^{27} \mathrm{Al}$ signal at $6.5 \mathrm{ppm}$ and ${ }^{1} \mathrm{H}$ signals at approximately 1.0 and $2.5 \mathrm{ppm}$ that likely correspond to distinct $-\mathrm{AlOH}$ moieties in $\mathrm{TAH}$. Additional weakly correlated signal intensity observed between the ${ }^{27} \mathrm{Al}$ signal at $9.0 \mathrm{ppm}$ and the ${ }^{1} \mathrm{H}$ signal at approximately $4.7 \mathrm{ppm}$ 


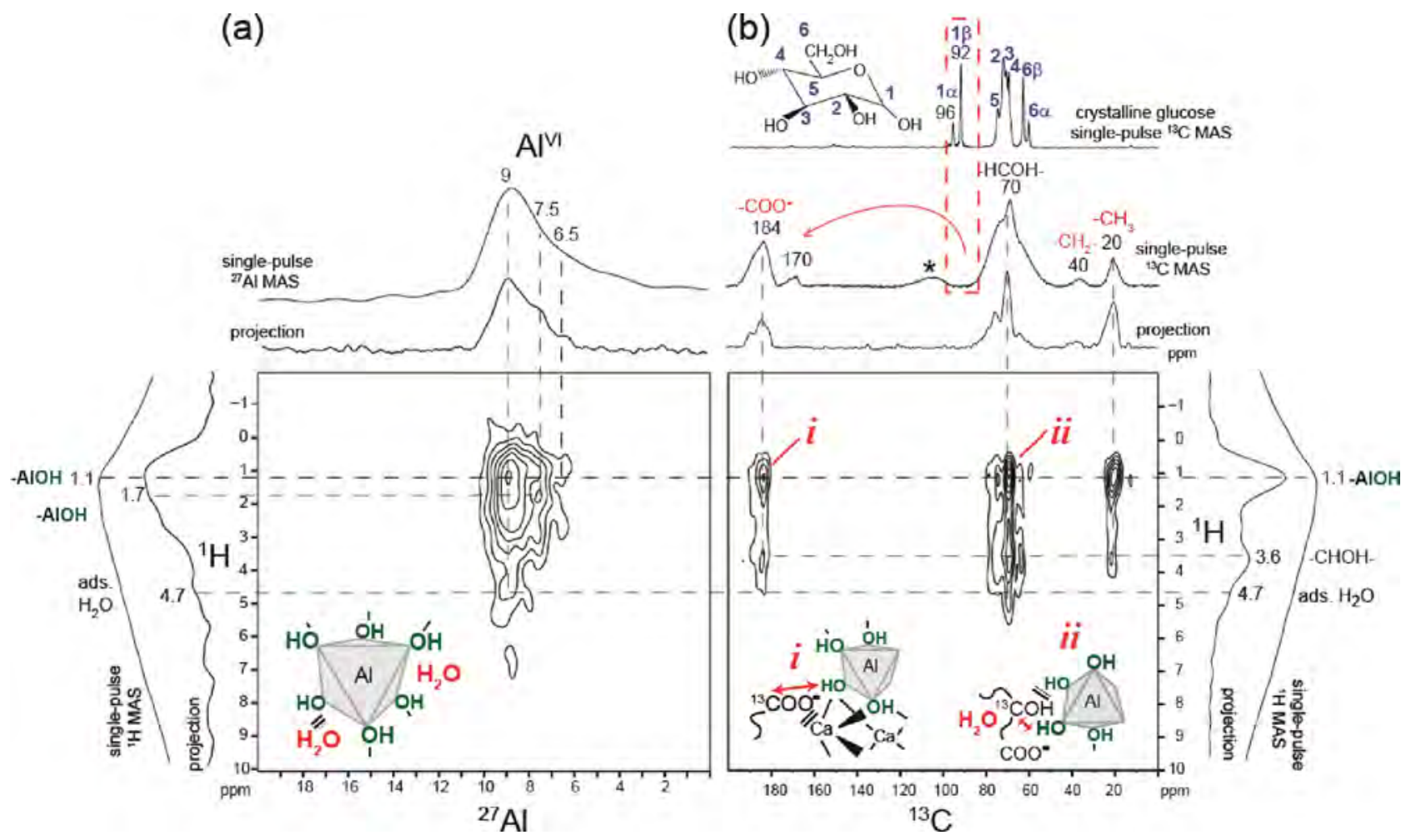

Figure 4. (a) Solid-state $2 \mathrm{D}{ }^{27} \mathrm{Al}\left\{{ }^{1} \mathrm{H}\right\}$ HETCOR NMR spectrum acquired at $18.8 \mathrm{~T}, 25^{\circ} \mathrm{C}, 10 \mathrm{kHz}$ MAS and (b) solid-state $2 \mathrm{D}{ }^{13} \mathrm{C}\left\{{ }^{1} \mathrm{H}\right\}$ HETCOR spectrum acquired at $11.7 \mathrm{~T}, 25{ }^{\circ} \mathrm{C}, 10 \mathrm{kHz}$ MAS for hydrated white Portland cement $\left(4 \mathrm{~h}, 95{ }^{\circ} \mathrm{C}\right)$ with $1 \%$ glucose $\left(99 \%{ }^{13} \mathrm{C}\right.$-labeled) by weight of cement. One-dimensional single-pulse ${ }^{27} \mathrm{Al}$ and ${ }^{13} \mathrm{C}$ MAS spectra are shown along the horizontal axes, and ${ }^{1} \mathrm{H}$ MAS spectra are shown along the vertical axes, respectively, for comparison with the $1 \mathrm{D}$ projections of the $2 \mathrm{D}$ spectra. The solid-state single-pulse $1 \mathrm{D}{ }^{13} \mathrm{C}$ MAS NMR spectrum acquired at $11.7 \mathrm{~T}, 25^{\circ} \mathrm{C}$, and $10 \mathrm{kHz}$ for crystalline glucose is shown along the top horizontal axis in $\mathrm{b}$. The inset in a shows a schematic diagram of the six-coordinate $\mathrm{Al}(\mathrm{OH})_{6}$ species in white Portland cement hydration products with adsorbed water. The insets in $b$ show glucose degradation moieties binding to aluminate hydrate surfaces in white Portland cement through (i) $-\mathrm{COO}^{-}$interactions and (ii) $-\mathrm{COH}$ hydrogen bonds. The corresponding ${ }^{13} \mathrm{C}-{ }^{1} \mathrm{H}$ dipole-dipole interactions observed in the spectra are indicated by red arrows. The symbol * indicates MAS side bands.

indicates the presence of adsorbed $\mathrm{H}_{2} \mathrm{O}$ in close $(<1 \mathrm{~nm})$ proximity to ${ }^{27} \mathrm{Al}^{\mathrm{VI}}$ species that comprise monosulfate. Importantly, the characterization of the different aluminate hydroxyl species and the assignments of their associated ${ }^{1} \mathrm{H}$ chemical shifts enable the interactions between the organic species and different aluminate hydration products to be probed by complementary solid-state $2 \mathrm{D}{ }^{13} \mathrm{C}\left\{{ }^{1} \mathrm{H}\right\}$ HETCOR NMR measurements.

Specifically, solid-state 2D ${ }^{13} \mathrm{C}\left\{{ }^{1} \mathrm{H}\right\}$ HETCOR NMR measurements are sensitive to dipole-dipole couplings between ${ }^{13} \mathrm{C}$ and ${ }^{1} \mathrm{H}$ nuclei in white Portland cement that occur when organic molecules are in close $(<1 \mathrm{~nm})$ proximity to aluminate hydroxyl moieties. For example, Figure $4 \mathrm{~b}$ shows the solid-state $1 \mathrm{D}$ single-pulse ${ }^{13} \mathrm{C}$ MAS spectrum (middle) of white Portland cement hydrated $\left(4 \mathrm{~h}, 95^{\circ} \mathrm{C}\right)$ in the presence of glucose, where ${ }^{13} \mathrm{C}$ signals are observed that are associated with organic carboxylate moieties $\left(-\mathrm{COO}^{-}, 170\right.$ and $\left.184 \mathrm{ppm}\right)$, carbinol species $(-\mathrm{CHOH}-, 55-85 \mathrm{ppm})$, and alkyl groups $\left(-\mathrm{CH}_{2}-, 40 \mathrm{ppm} ;-\mathrm{CH}_{3}, 20 \mathrm{ppm}\right)$. Compared to the spectrum of crystalline glucose (Figure $4 b$, top), new ${ }^{13} \mathrm{C}$ signals are observed at 184 and $170 \mathrm{ppm}$, which appear in a region of the spectrum that is characteristic of carboxylic acids. The signal at $184 \mathrm{ppm}$ corresponds well to those measured for glyceric and gluconic acids (Supporting Information, Figure S2), which were shown to be present in the solution extract of the gray oilwell cement slurry (Figure $2 \mathrm{~b}$ ). Additional ${ }^{13} \mathrm{C}$ signals at 40 and $20 \mathrm{ppm}$ are also observed in the ${ }^{13} \mathrm{C}$ region associated with $-\mathrm{CH}_{2}-$ and $-\mathrm{CH}_{3}$ alkyl species, respectively.
Importantly, the absence of $\mathrm{C} 1 \alpha(96 \mathrm{ppm})$ and $\mathrm{C} 1 \beta$ (92 ppm) signals in the ${ }^{13} \mathrm{C}$ MAS spectrum establishes that molecular glucose is not adsorbed on white Portland cement. Interestingly, the solid-state ${ }^{13} \mathrm{C}$ MAS signals centered at $20\left(-\mathrm{CH}_{3}\right)$, $40\left(-\mathrm{CH}_{2}-\right)$, and $170 \mathrm{ppm}\left(-\mathrm{COO}^{-}\right)$are not observed in the solution-state ${ }^{13} \mathrm{C}$ APT NMR spectrum of cement slurry extract solutions containing glucose (Figure $2 \mathrm{~b}$ ), indicating that different glucose degradation species preferentially adsorb onto cement particle surfaces.

Although the solid-state 1D single-pulse ${ }^{1} \mathrm{H}$ MAS spectrum (Figure $4 \mathrm{~b}$, right) consists of a broad, featureless line shape, the 2D ${ }^{13} \mathrm{C}\left\{{ }^{1} \mathrm{H}\right\}$ HETCOR spectrum reveals distinct interactions between ${ }^{13} \mathrm{C}$ moieties and a subset of the ${ }^{1} \mathrm{H}$ species present. In particular, strong intensity correlations are observed for the ${ }^{13} \mathrm{C}$ signals at $184 \mathrm{ppm}$ from carboxylate groups and at $70 \mathrm{ppm}$ from carbinol moieties with the ${ }^{1} \mathrm{H}$ signals at 3.6 and $1.1 \mathrm{ppm}$. The ${ }^{1} \mathrm{H}$ signal observed at $3.6 \mathrm{ppm}$ is assigned to the carbinol protons ( $-\mathrm{CHOH}-$ ) associated with glucose degradation products, reflecting intramolecular dipolar interactions from directly bonded species. More importantly, a comparison of the ${ }^{1} \mathrm{H}$ chemical shifts in the $2 \mathrm{D}{ }^{27} \mathrm{Al}\left\{{ }^{1} \mathrm{H}\right\}$ and ${ }^{13} \mathrm{C}\left\{{ }^{1} \mathrm{H}\right\}$ HETCOR spectra (Figure $4 \mathrm{a}, \mathrm{b}$ ) acquired on the same sample establishes that the ${ }^{1} \mathrm{H}$ signal at $1.1 \mathrm{ppm}$ arises from - $\mathrm{AlOH}$ hydroxyl groups that compose calcium aluminate monosulfate. Although the ${ }^{1} \mathrm{H}$ signal at $1.1 \mathrm{ppm}$ is in a region of the spectrum that could also be associated with the $-\mathrm{CH}_{3}$ proton species, much weaker intensity correlations in the $2 \mathrm{D}$ spectrum are expected for intramolecular ${ }^{13} \mathrm{C}-{ }^{1} \mathrm{H}$ dipolar interactions between distant 
(a)

(b)

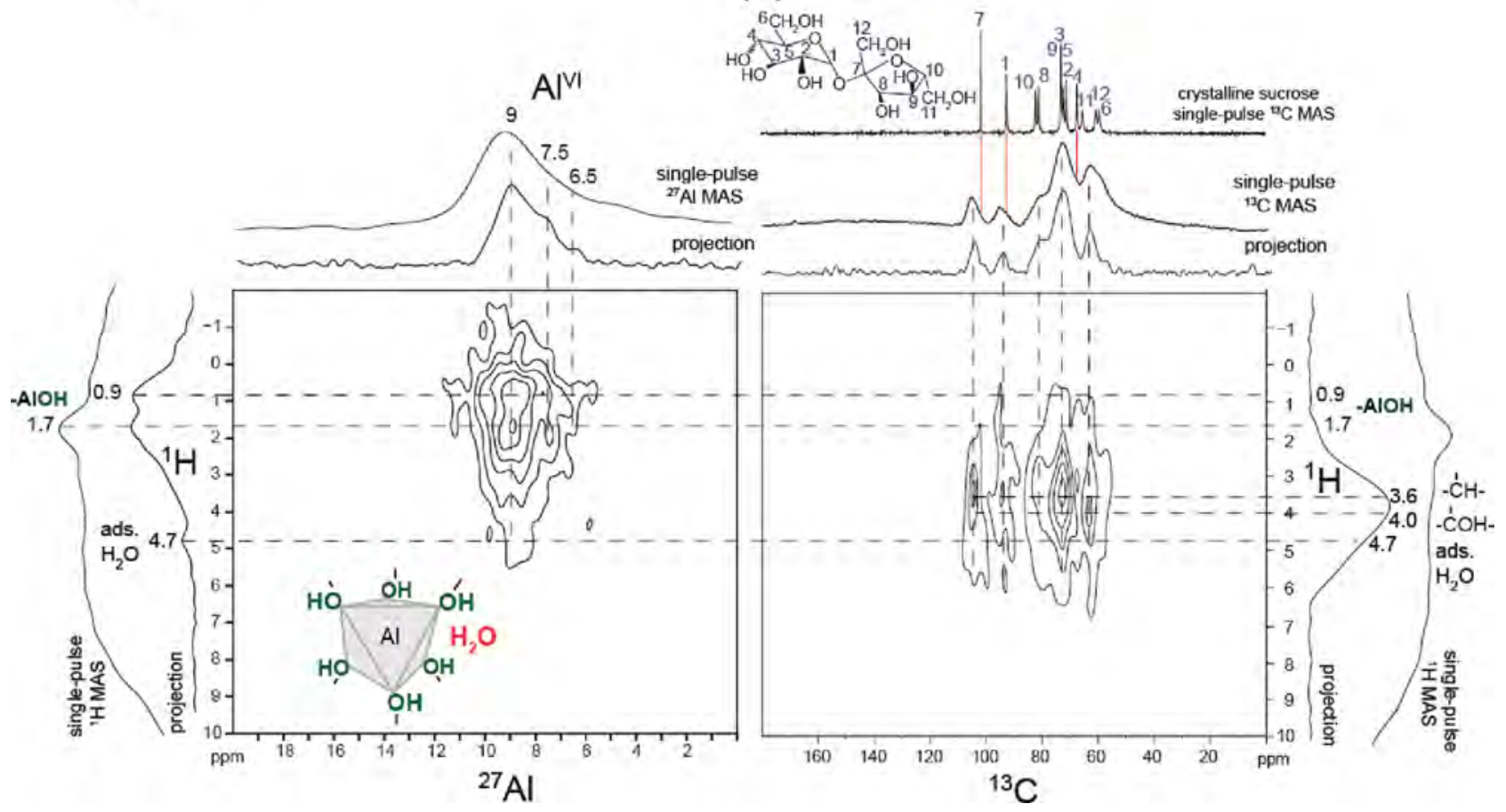

Figure 5. (a) Solid-state $2 \mathrm{D}{ }^{27} \mathrm{Al}\left\{{ }^{1} \mathrm{H}\right\}$ HETCOR NMR spectrum acquired at $18.8 \mathrm{~T}, 25^{\circ} \mathrm{C}, 10 \mathrm{kHz}$ MAS and (b) solid-state $2 \mathrm{D}{ }^{13} \mathrm{C}\left\{{ }^{1} \mathrm{H}\right\}$ HETCOR NMR spectrum acquired at $11.7 \mathrm{~T}, 25{ }^{\circ} \mathrm{C}, 10 \mathrm{kHz}$ MAS for hydrated white Portland cement $\left(4 \mathrm{~h}, 95{ }^{\circ} \mathrm{C}\right)$ with $1 \%$ sucrose $\left(99 \%{ }^{13} \mathrm{C}\right.$-labeled) by weight of cement. One-dimensional single-pulse ${ }^{27} \mathrm{Al}$ and ${ }^{13} \mathrm{C}$ MAS spectra are shown along the horizontal axes, and ${ }^{1} \mathrm{H}$ MAS spectra are shown along the vertical axes, respectively, for comparison with the $1 \mathrm{D}$ projections of the $2 \mathrm{D}$ spectra. The solid-state single-pulse $1 \mathrm{D}{ }^{13} \mathrm{C}$ MAS NMR spectrum acquired at $11.7 \mathrm{~T}, 25^{\circ} \mathrm{C}$, and $10 \mathrm{kHz}$ for crystalline sucrose is shown along the top horizontal axis of b. Solid red lines are shown in b for comparison with the ${ }^{13} \mathrm{C}$ isotropic chemical shifts in crystalline and adsorbed sucrose. The inset in a shows a schematic diagram of the six-coordinate $\mathrm{Al}(\mathrm{OH})_{6}$ species in white Portland cement hydration products with adsorbed water.

(i.e., $\geq$ two bonds) ${ }^{13} \mathrm{C}$ and ${ }^{1} \mathrm{H}$ moieties. ${ }^{60}$ Consequently, the strong intensity correlations observed in the $2 \mathrm{D}{ }^{13} \mathrm{C}\left\{{ }^{1} \mathrm{H}\right\}$ HETCOR spectrum for the ${ }^{13} \mathrm{C}$ signals at 184 and $70 \mathrm{ppm}$ with the ${ }^{1} \mathrm{H}$ signal at $1.1 \mathrm{ppm}$ indicate that $-\mathrm{COO}^{-}$and carbinol moieties are in close proximity $(<1 \mathrm{~nm})$ to monosulfate hydroxyl groups. Carboxylate groups bind to aluminate surfaces in aqueous environments through electrostatic interactions with surface calcium sites (Figure $4 \mathrm{~b}$, inset i), whereas $-\mathrm{COH}$ carbinol species can form hydrogen bonds with surface $-\mathrm{AlOH}$ moieties (Figure 4b, inset ii). Additional correlated signal intensity in Figure $4 \mathrm{~b}$ is observed at $20 \mathrm{ppm}$ in the ${ }^{13} \mathrm{C}$ dimension and at $1.1 \mathrm{ppm}$ in the ${ }^{1} \mathrm{H}$ dimension, which arises principally from intramolecular dipolar interactions associated with $-\mathrm{CH}_{3}$ species. ${ }^{60}$ Interestingly, intensity correlations are not observed between the ${ }^{13} \mathrm{C}$ signal centered at $170 \mathrm{ppm}$ and any of the ${ }^{1} \mathrm{H}$ signals, which may reflect the lower concentration of this $-\mathrm{COO}^{-}$species or indicate that they do not adsorb on aluminate hydrate surfaces. The results presented here for a complicated cement mixture are consistent with previous $2 \mathrm{D}$ ${ }^{13} \mathrm{C}\left\{{ }^{1} \mathrm{H}\right\}$ measurements ${ }^{10}$ of tricalcium aluminate (alone) hydrated in the presence of glucose $\left(4 \mathrm{~h}, 95^{\circ} \mathrm{C}, 1 \%\right.$ glucose bwos), which showed that glucose degradation products adsorb onto, or are intercalated within, aluminate hydration products. Recent work suggests ${ }^{61,62}$ that strong molecular interactions may lead to the incorporation or intercalation of organic moieties within the aluminate hydration products.

For hydrated white Portland cement, the foregoing analyses unambiguously establish strong intermolecular interactions between the carboxylate and carbinol moieties found in glucose degradation products and the $-\mathrm{AlOH}$ groups of calcium aluminate monosulfate. These results point to the strong adsorption of saccharinic acids (or other carboxylic acid products of glucose degradation) onto aluminate hydration products. Important and direct consequences of this are the diminished adsorption coverages of the organic acids on other cement surfaces, notably nonhydrated tricalcium silicate, which accounts in part for their reduced overall efficacy to inhibit cement hydration.

Sucrose Interactions in White Portland Cement. In contrast to cements hydrated in the presence of glucose, similar measurements under otherwise identical hydration conditions show that sucrose does not degrade in white Portland cement slurries and adsorbs weakly onto aluminate hydration products. The $2 \mathrm{D}{ }^{27} \mathrm{Al}\left\{{ }^{1} \mathrm{H}\right\}$ HETCOR spectrum of white Portland cement hydrated $\left(4 \mathrm{~h}, 95^{\circ} \mathrm{C}\right)$ in the presence of $1 \%$ sucrose bwoc is shown in Figure 5 a and exhibits similar intensity correlations as observed for cement hydrated with glucose (Figure $4 \mathrm{a}$ ). These include ${ }^{27} \mathrm{Al}$ NMR signals associated with monosulfate $(9.0 \mathrm{ppm})$, tetracalcium aluminate hydrate $(7.5 \mathrm{ppm})$, and TAH $(6.5 \mathrm{ppm})$, which are correlated with ${ }^{1} \mathrm{H}$ signals that correspond to different $-\mathrm{AlOH}$ species (0.9-2.5 $\mathrm{ppm}$ ) within the aluminate hydration products. Compared to cement hydrated with glucose, the ${ }^{27} \mathrm{Al}$ signal associated with calcium aluminate monosulfate exhibits a more pronounced correlated intensity with the ${ }^{1} \mathrm{H}$ signal at $1.7 \mathrm{ppm}$ rather than that at $1.1 \mathrm{ppm}$, indicating dissimilar local monosulfate $-\mathrm{AlOH}$ environments that are hypothesized to be influenced by different interactions with the saccharides. 
Specific interactions between adsorbed sucrose molecules and aluminate species are probed by solid-state $2 \mathrm{D}{ }^{13} \mathrm{C}\left\{{ }^{1} \mathrm{H}\right\}$ HETCOR measurements conducted on the same sample of white Portland cement hydrated $\left(4 \mathrm{~h}, 95^{\circ} \mathrm{C}\right)$ in the presence of $1 \%$ sucrose bwoc (99\% ${ }^{13} \mathrm{C}$-labeled). Broadened signals associated with all of the distinct ${ }^{13} \mathrm{C}$ atoms in sucrose appear in the quantitative $1 \mathrm{D}$ single-pulse ${ }^{13} \mathrm{C}$ MAS spectrum of hydrated white Portland cement (Figure 5b, middle), which establishes that sucrose molecules adsorb intact at cement particle surfaces. Compared to the spectrum of crystalline sucrose (Figure $5 \mathrm{~b}$, top), the broadened ${ }^{13} \mathrm{C}$ signals are due to heterogeneous local compositions or structures of the white Portland cement surfaces or differences in the conformations of the adsorbed molecules that lead to a distribution of local ${ }^{13} \mathrm{C}$ environments. Although broadened, the relative integrated ${ }^{13} \mathrm{C}$ signal intensities are consistent with the populations of the distinct carbon sites within the sucrose molecules. In the $2 \mathrm{D}$ ${ }^{13} \mathrm{C}\left\{{ }^{1} \mathrm{H}\right\}$ HETCOR spectrum, intensity correlations are observed between all of the ${ }^{13} \mathrm{C}$ signals and the broad ${ }^{1} \mathrm{H}$ signal centered at $3.6 \mathrm{ppm}$, as similarly seen for crystalline sucrose (Supporting Information, Figure S6), indicating that they are associated with intramolecular dipole-dipole interactions involving $>\mathrm{CH}-$ and $>\mathrm{COH}-$ moieties. Importantly, only very weak intensity correlations are observed between the ${ }^{13} \mathrm{C}$ signals associated with sucrose and the ${ }^{1} \mathrm{H}$ signal centered at $1.7 \mathrm{ppm}$ that corresponds to monosulfate $-\mathrm{AlOH}$ moieties. This establishes that small concentrations of ${ }^{13} \mathrm{C}$ sucrose moieties are in close molecular proximity to hydrated monosulfate species. Unlike the situation for glucose, the intensity correlations observed in the $2 \mathrm{D}{ }^{13} \mathrm{C}\left\{{ }^{1} \mathrm{H}\right\}$ HETCOR spectrum of hydrating white Portland cement establish that sucrose does not bind strongly to calcium aluminate monosulfate surfaces, leading to higher local coverages at other cement surfaces. This indicates that sucrose binds selectively on silicate or nonhydrated aluminate species in white Portland cement to inhibit hydration processes.

Furthermore, comparisons of the isotropic ${ }^{13} \mathrm{C}$ chemical shifts for crystalline sucrose versus sucrose adsorbed on white Portland cement allow specific ${ }^{13} \mathrm{C}$ moieties to be identified that interact strongly with inorganic species in the hydrating cement. The adsorption or complexation of an organic molecule to an inorganic surface or ion can alter the local electronic environments of ${ }^{13} \mathrm{C}$ species, leading to changes in their isotropic chemical shifts. Such comparisons establish that the isotropic ${ }^{13} \mathrm{C}$ chemical shifts of carbon sites $\mathrm{C} 1, \mathrm{C} 4$, and $\mathrm{C} 7$ in sucrose molecules (as labeled in Figure $5 \mathrm{~b}$, inset) are each displaced by 2 to $3 \mathrm{ppm}$ upon adsorption, compared to crystalline sucrose; all other ${ }^{13} \mathrm{C}$ chemical shifts are very similar $(|\delta|<1 \mathrm{ppm})$. This indicates that sucrose carbon sites C1, C4, and C7 interact most strongly at white Portland cement surfaces, consistent with the presence of multiple interaction sites on the disaccharide sucrose molecule. Such interactions are hypothesized to occur with hydroxyl groups that are associated with the $\mathrm{C} 4$ moiety and $\mathrm{Ca}^{2+}$ cations near particle surfaces. They are consistent with previous reports that suggest that 1,3-diol moieties in sucrose in an equatorial-axialequatorial configuration, such as the $\mathrm{C} 4$ site, promote $\mathrm{Ca}^{2+}$ complexation in saccharides. ${ }^{15,18,44,63}$ The isotropic ${ }^{13} \mathrm{C}$ chemical shifts of the $\mathrm{C} 1$ and $\mathrm{C} 7$ sucrose species are thought to be altered by local conformational changes associated with the proximate binding of $\mathrm{Ca}^{2+}$ to the deprotonated $\mathrm{C} 8$ moiety $\left(\mathrm{p} K_{\mathrm{a}} \sim 12.6\right)$. Importantly, the ${ }^{13} \mathrm{C}$ chemical shifts of sucrose adsorbed on hydrating white Portland cement are nearly identical to those observed in the $2 \mathrm{D}{ }^{13} \mathrm{C}\left\{{ }^{1} \mathrm{H}\right\}$ HETCOR spectrum of tricalcium silicate $\left(\mathrm{C}_{3} \mathrm{~S}\right)$ alone, hydrated under otherwise identical conditions $\left(4 \mathrm{~h}, 95{ }^{\circ} \mathrm{C}\right) .{ }^{10}$ Such measurements established strong molecular interactions between $-\mathrm{SiOH}$ species and all ${ }^{13} \mathrm{C}$ moieties in adsorbed sucrose molecules, consistent with their planarlike adsorption at $\mathrm{C}_{3} \mathrm{~S}$ surfaces. Two-dimensional ${ }^{29} \mathrm{Si}\left\{{ }^{1} \mathrm{H}\right\}$ HETCOR NMR could not be acquired under similar experimental conditions for hydrating white Portland cement because of the low concentrations $(<1$ wt \%) of $-\mathrm{SiOH}$ moieties. Nevertheless, this suggests that sucrose is adsorbed near tricalcium silicate surfaces in white Portland cement and that multiple adsorption and complexation sites are present within individual sucrose molecules.

Additionally, sucrose-cation complexation is expected to lead to the formation of aggregate structures (e.g., $-\mathrm{Ca}^{2+}-$ sucrose- $\mathrm{Ca}^{2+}-$ sucrose-) that promote the formation of several adsorbed sucrose layers at hydrating tricalcium silicate surfaces. The broad, solid-state $1 \mathrm{D}{ }^{13} \mathrm{C}$ MAS signals observed in the spectra of white Portland cement (Figure $5 \mathrm{~b}$, middle) hydrated in the presence of sucrose indicate a distribution of local ${ }^{13} \mathrm{C}$ environments that are consistent with sucrose-Ca ${ }^{2+}$ complexation. Separate quantitative $1 \mathrm{D}$ single-pulse ${ }^{13} \mathrm{C}$ MAS spectra (Supporting Information, Figure S7) notably establish that the local ${ }^{13} \mathrm{C}$ environments of sucrose species adsorbed on white Portland cement are very similar to those in a neat sucrose- $\mathrm{Ca}^{2+}$ precipitate prepared under strongly alkaline conditions. We hypothesize that $\mathrm{Ca}^{2+}$ cations interact with more than one sucrose molecule to promote their aggregation near hydrating cement surfaces, particularly at tricalcium silicate surface sites. This is consistent with separate light-scattering and viscosity measurements ${ }^{44}$ that have reported sucrose aggregation in aqueous calcium hydroxide solutions. Additionally, recent surface forces measurements have reported the formation of four to five adsorbed sucrose layers at aluminosilicate mica surfaces from alkaline $\mathrm{NaOH}$ solutions ( 0.2 wt \% sucrose, $\mathrm{pH} 12.7,25{ }^{\circ} \mathrm{C}$ ) that simulate conditions found in hydrating cements. ${ }^{10}$ Quantitative analyses indicated that sucrose $-\mathrm{Na}^{+}$cation complexation near aluminosilicate surfaces appears to promote multilayer adsorption. These results establish that, unlike glucose, sucrose adsorbs intact at white Portland cement surfaces and that multiple binding or complexation sites within sucrose molecules are expected to promote the formation of aggregated sucrose layers near hydrating tricalcium silicate surfaces.

Saccharide-Mediated Hydration of Gray Oilwell Cement. Analogous molecular-level NMR measurements probe saccharide interactions at aluminate surfaces in hydrating gray oilwell cements, indicating that the adsorption of glucose degradation products or sucrose is similar to that observed for white Portland cement. As above, the extents of hydration of gray oilwell cements and the relative quantities of the different silicate and NMR-visible aluminate hydration products can be estimated by solid-state $1 \mathrm{D}$ single-pulse ${ }^{29} \mathrm{Si}$ and ${ }^{27} \mathrm{Al}$ MAS NMR measurements (Supporting Information, Figure S8) of gray oilwell cement hydrated $\left(4 \mathrm{~h}, 95^{\circ} \mathrm{C}\right)$ in the presence of $1 \%$ glucose or sucrose bwoc $\left(99 \%{ }^{13} \mathrm{C}\right.$-labeled). Analyses of the $1 D{ }^{29} \mathrm{Si}$ MAS spectra (Supporting Information, Figure S8a,b) establish that no detectable quantities $(<1$ wt $\%)$ of $Q^{1}$ or $Q^{229} \mathrm{Si}$ species associated with calcium silicate hydrates are formed in the presence of $1 \%$ glucose or sucrose bwoc. As observed for white Portland cement, additional solid-state 1D single-pulse ${ }^{29} \mathrm{Si} \mathrm{MAS}$ measurements (Supporting Information, Figure S9) of gray oilwell cement hydrated under identical 
conditions but for longer periods of time (e.g., $8 \mathrm{~h}$ ) establish that sucrose delays the formation of calcium silicate hydrates more effectively than glucose. One-dimensional single-pulse ${ }^{27} \mathrm{Al}$ MAS spectra (Supporting Information, Figure S8c,d) show that similar heterogeneous compositions of aluminate hydration products are formed in the presence of both glucose and sucrose. The extent of tetracalcium aluminoferrite hydration cannot be determined directly from the ${ }^{27} \mathrm{Al}$ MAS spectra because the presence of para/ferromagnetic iron species reduces the visibility of ${ }^{27} \mathrm{Al} \mathrm{NMR}$ signals from nearby moieties, complicating or obscuring their detection. On the basis of quantitative spin-counting analyses, ${ }^{32}$ approximately $70 \%$ of the total ${ }^{27} \mathrm{Al}$ species in the gray oilwell cements hydrated in the presence of glucose or sucrose are estimated to be NMR-visible. These results establish that the extents of aluminate and silicate hydration in gray oilwell cements containing $1 \%$ glucose or sucrose bwoc as well as the composition of the aluminate hydration products are very similar following hydration for $4 \mathrm{~h}$ at $95{ }^{\circ} \mathrm{C}$. Overall, the hydration behavior of gray oilwell cement is thus similar to the saccharide-mediated hydration of white Portland cement, for which hydration inhibition is correlated with the extension of the induction period prior to the onset of calcium silicate hydrate formation.

Likewise, solid-state 2D ${ }^{13} \mathrm{C}\left\{{ }^{1} \mathrm{H}\right\}$ HETCOR NMR measurements establish that glucose and sucrose adsorption are similar in gray oilwell and white Portland cements and that glucose degradation products adsorb onto aluminate hydration products whereas sucrose molecules do not. The $2 \mathrm{D}{ }^{13} \mathrm{C}\left\{{ }^{1} \mathrm{H}\right\}$ HETCOR spectra of gray oilwell cement hydrated in the presence of glucose or sucrose (Supporting Information, Figure S10a,b, respectively) show almost identical correlated signal intensities to those observed in white Portland cement (Figures $4 \mathrm{~b}$ and $5 \mathrm{~b}$ ). The hydration of gray oilwell cements in the presence of glucose or sucrose thus reflects similar respective adsorption behaviors as observed for white Portland cements, including the fact that glucose degradation species adsorb to much greater extents than does sucrose on aluminate surfaces. Whether and to what extents the saccharides or their degradation products are molecularly close to paramagnetic iron species in the hydrated gray oilwell cements can be estimated by quantifying and comparing the integrated ${ }^{13} \mathrm{C}$ NMR signal intensities observed in their solid-state $1 \mathrm{D}$ singlepulse ${ }^{13} \mathrm{C}$ MAS spectra with an external spin-counting standard. The presence of para/ferromagnetic iron-containing species in gray oilwell cements results in significantly shorter spin-lattice $\left(T_{1}\right)$ relaxation times of nearby NMR-active species that can result in a loss of NMR visibility, even for spin $^{-1} / 2$ nuclei such as ${ }^{13} \mathrm{C}$. For gray oilwell cement hydrated in the presence of $1 \mathrm{wt}$ $\%$ glucose, a comparison of the relative integrated ${ }^{13} \mathrm{C}$ signal intensities of the single-pulse ${ }^{13} \mathrm{C}$ MAS spectrum (Supporting Information, Figure S10a, top) with an external spin-counting standard indicates that approximately $45 \%$ of the ${ }^{13} \mathrm{C}$ species adsorbed onto the cement surfaces are visible. In contrast, analogous spin-counting analyses (Supporting Information, Figure S10b, top) for gray oilwell cement hydrated in the presence of sucrose under identical conditions establish that approximately $70 \%$ of the ${ }^{13} \mathrm{C}$ species are NMR-visible. The lower NMR visibility of the ${ }^{13} \mathrm{C}$ species associated with the glucose degradation products, compared to sucrose, indicates that they are in closer molecular proximity to para/ ferromagnetic Fe species in gray oilwell cement. This suggests that a larger quantity of glucose degradation products are adsorbed onto tetracalcium aluminoferrite or other iron- containing aluminate hydration products in gray oilwell cement, compared to sucrose. This is consistent with the $2 \mathrm{D}{ }^{13} \mathrm{C}\left\{{ }^{1} \mathrm{H}\right\}$ HETCOR analyses (Figures 4 and 5) that established the adsorption of glucose degradation species at aluminate hydrate surfaces in much higher concentrations than for sucrose.

Saccharide-Mediated Cement Hydration. The complementary 2D and quantitative 1D NMR measurements establish that, in contrast to glucose, sucrose does not degrade or adsorb strongly on aluminate hydration products and suggest that hydration inhibition likely involves the adsorption of glucose degradation species or sucrose at tricalcium silicate surfaces. Such adsorption of organic species at tricalcium silicate surfaces is consistent with the delayed formation of calcium silicate hydrates in both white Portland and gray oilwell cements hydrated in the presence of small quantities ( $\leq 1 \%$ bwoc) of these different saccharides. However, as outlined by Cheung et al., ${ }^{12}$ whether hydration inhibition is due predominantly to the adsorption (or precipitation) of organic species onto initially nonhydrated $\mathrm{C}_{3} \mathrm{~S}$ surfaces versus that onto hydrated products (e.g., $\mathrm{Ca}(\mathrm{OH})_{2}$ or calcium silicate hydrates) has remained elusive and unresolved. In the former case, organic species may adsorb on nonhydrated tricalcium silicate species in cements to slow the dissolution of ions (e.g., $\mathrm{H}_{3} \mathrm{SiO}_{4}{ }^{-}$or $\mathrm{Ca}^{2+}$ ) from particle surfaces, thereby delaying the subsequent precipitation of hydration products. Such adsorption of organic species onto initially nonhydrated surfaces may also interfere with the nucleation of hydration products on cement particle surfaces. ${ }^{12}$ Alternatively, organic species can adsorb directly onto newly formed hydration products to slow additional growth (e.g., by "poisoning" growth sites) of $\mathrm{Ca}(\mathrm{OH})_{2}$ or $\mathrm{C}-\mathrm{S}-\mathrm{H}$. Here, the quantitative solid-state $1 \mathrm{D}$ single-pulse ${ }^{29} \mathrm{Si}$ MAS NMR measurements (Supporting Information, Figures S4a,b and S8a,b) of white Portland and gray oilwell cements hydrated in the presence of glucose and sucrose establish that no measurable quantities ( $<1$ wt $\%$ of total ${ }^{29} \mathrm{Si}$ species) of calcium silicate hydrates are present after $4 \mathrm{~h}$ at $95{ }^{\circ} \mathrm{C}$.

Whether organic species adsorb onto initially nonhydrated or hydrated surface species can be probed in more detail by examining the composition of the silicate surface species by solid-state ${ }^{29} \mathrm{Si}$ NMR measurements that establish the presence of non-cross-linked $Q^{0}$ silicate monomers and the absence of cross-linked $Q^{1}$ or $Q^{2}$ species that are associated with calcium silicate hydrates. Specifically, Figure 6a shows the solid-state single-pulse 1D ${ }^{29} \mathrm{Si}$ MAS NMR spectrum acquired at room temperature for hydrated white Portland cement $\left(4 \mathrm{~h}, 95^{\circ} \mathrm{C}\right)$ with $1 \%$ sucrose by weight of cement and acquired with 2000 signal averages. For comparison, the solid-state $1 \mathrm{D}{ }^{29} \mathrm{Si}\left\{{ }^{1} \mathrm{H}\right\}$ CPMAS NMR spectrum of the same sample but acquired with $4 \times 10^{4}$ signal averages is shown in Figure $6 \mathrm{~b}$. The ${ }^{29} \mathrm{Si}\left\{{ }^{1} \mathrm{H}\right\}$ CPMAS measurements are sensitive to dipole-dipole-coupled ${ }^{29} \mathrm{Si}$ and ${ }^{1} \mathrm{H}$ nuclei such as those associated with hydroxylated or hydrated silicate moieties. Figure $6 \mathrm{~b}$ shows broad (3 ppm fwhm) and very weak ${ }^{29} \mathrm{Si}$ signal intensity centered at $-75 \mathrm{ppm}$ in the region that corresponds to monomeric $Q^{0}{ }^{29} \mathrm{Si}$ species that are in close molecular proximity $(<1 \mathrm{~nm})$ to hydroxyl groups or adsorbed water. Such $Q^{0}$ silicate species are most likely associated with partially hydroxylated $\mathrm{C}_{3} \mathrm{~S}$ sites (e.g., $\mathrm{SiO}(\mathrm{OH})_{3}{ }^{-}$or $\left.\mathrm{SiO}_{2}(\mathrm{OH})_{2}{ }^{2-}\right)$ on cement particle surfaces and may include small quantities of silicate anions precipitated from the cement slurry solution during the freeze-drying of the sample. Importantly, no $Q^{1}$ or $Q^{2}$ species associated with hydrated silicate species (e.g., $\mathrm{C}-\mathrm{S}-\mathrm{H})$ are detected $(\leq 0.2 \mathrm{wt}$ $\%)$, even after prolonged signal averaging. These results suggest 

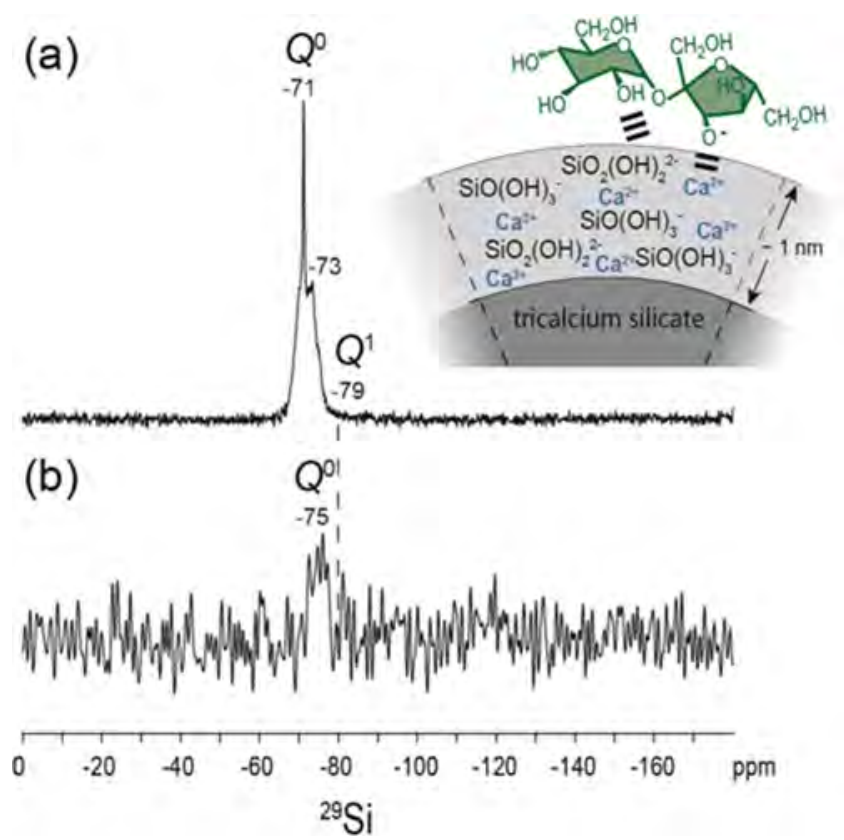

Figure 6. Solid-state 1D (a) single-pulse ${ }^{29} \mathrm{Si}$ MAS NMR spectrum (2000 signal averages) and (b) ${ }^{29} \mathrm{Si}\left\{{ }^{1} \mathrm{H}\right\}$ CPMAS NMR spectrum $(4 \times$ $10^{4}$ signal averages) acquired at $11.7 \mathrm{~T}, 25{ }^{\circ} \mathrm{C}, 10 \mathrm{kHz}$ MAS for hydrated white Portland cement with $1 \%$ sucrose by weight of cement. (Inset) Schematic diagram of a sucrose molecule adsorbed onto a hydroxylated $Q^{029} \mathrm{Si}$ surface species.

that, under alkaline conditions in the presence of sucrose, small quantities of hydroxylated $Q^{0}{ }^{29} \mathrm{Si}$ species initially form on the surfaces of cement particles and subsequently are converted to cross-linked $Q^{1}$ or $Q^{2}$ species in calcium silicate hydrates. These partially hydroxylated $Q^{0}{ }^{29} \mathrm{Si}$ species are likely proximate to calcium cations for charge compensation (Figure 6, inset). This observation is consistent with previous experimental ${ }^{64}$ and theoretical results ${ }^{9}$ that suggest the presence of "intermediate" hydroxylated silicate surface species, which subsequently crosslink to form calcium silicate hydrates at ambient temperatures. These results indicate that the adsorption of organic species at hydroxylated $Q^{0}$ tricalcium silicate surface sites delays the latter's hydration to cross-linked $Q^{1}$ or $Q^{2}$ species in $C-S-H$, accounting for the extended induction period. Small quantities of $\mathrm{Ca}(\mathrm{OH})_{2}$ that could precipitate during initial cement hydration (if present) may also influence surface adsorption and $\mathrm{C}-\mathrm{S}-\mathrm{H}$ formation. ${ }^{51}$ Furthermore, although the organic species also likely adsorb onto the calcium silicate hydrates, at early hydration times (e.g., $4 \mathrm{~h}$ ), no $\mathrm{C}-\mathrm{S}-\mathrm{H}$ species are observed. Our results thus strongly suggest that it is the initial formation, rather than the growth, of the calcium silicate hydrates that is inhibited by the adsorbed organic species.

The NMR analyses indicate that sucrose is much more effective at inhibiting cement hydration than glucose because of their different adsorption selectivities and binding strengths on cement particle surfaces. First, compared to glucose, which adsorbs nonselectively at both aluminate and silicate surfaces, sucrose appears to adsorb selectively at tricalcium silicate surfaces, leading to higher local surface coverages and crucial passivation of surface $\mathrm{C}_{3} \mathrm{~S}$ sites that delay the formation of calcium silicate hydrates. The nonselective adsorption and intercalation of glucose degradation species at aluminate hydrate surfaces is thought to result from their much higher acid dissociation constants, which promote electrostatic interactions at cationic calcium surface sites (e.g., saccharinic acids, $\mathrm{p} K_{\mathrm{a}}<4$, vs sucrose, $\mathrm{p} K_{\mathrm{a}} 12.6$ ). Additionally, the lowermolecular-weight carboxylic and saccharinic degradation species may be more easily intercalated within the aluminate hydration products for steric reasons. These results indicate that, compared to sucrose, the relatively strong binding of carboxylate-containing species at aluminate surfaces leads to lower surface coverages at tricalcium silicate sites and correspondingly less effective hydration inhibition of silicate species.

Multiple interaction sites on nondegraded sucrose molecules lead to strong binding at initially nonhydrated, but hydroxylated, $\mathrm{C}_{3} \mathrm{~S}$ surfaces, cation complexation, and the formation of multiple adsorbed layers. As discussed, the presence of at least two sucrose interaction sites can promote the formation of aggregate structures (e.g., $-\mathrm{Ca}^{2+}-$ sucrose $-\mathrm{Ca}^{2+}-$ sucrose-) and several adsorbed sucrose layers, especially at higher sucrose concentrations. Conversely, the linear carboxylic acids that are the principal glucose degradation species appear to bind more weakly at hydrating cement particle surfaces. Electrostatic interactions between the $-\mathrm{COO}^{-}$groups and $\mathrm{Ca}^{2+}$ cations are expected to promote single-site end-on binding at $\mathrm{C}_{3} \mathrm{~S}$ surfaces, leading to monolayer-like adsorption. This is consistent with recent surface forces measurements that establish that glucose degradation products bind weakly to aluminosilicate mica surfaces from alkaline solutions, whereas sucrose molecules bind strongly and form multiple layers that are 3 to $4 \mathrm{~nm}$ thick. ${ }^{10}$ Maltodextrin represents an intermediate case in which it partially degrades to a combination of carboxylic acids and higher-molecular-weight oligomeric dextrins (Supporting Information, Figure S11) that adsorb on cement particle surfaces. Oligomeric saccharide species with ring structures will likely adsorb in a fashion similar to that of sucrose, whereas other low-molecular-weight carboxylic acid degradation products are expected to adsorb like the carboxylic or saccharinic acid species observed for glucose. The data presented here support the hypothesis that nondegraded sucrose molecules form relatively stable, and less-permeable adsorbed layers at tricalcium silicate surfaces. In contrast, glucose and maltodextrin degradation products, consisting of linear saccharinic or other carboxylic acids, adsorb as less-stable monolayers that are less effective at inhibiting water diffusion to hydrating surfaces. In the presence of saccharides, the onset of the formation of calcium silicate hydrates (corresponding to the end of the tricalcium silicate induction period) is hypothesized to depend directly on the stability of the adsorbed organic layer, which affects the ingress of water and interferes with the formation of calcium silicate hydrates at particle surfaces. The integrities of such adsorbed layers may be compromised by surface reactions, thermal degradation, desorption, increased local pressure, or particle-particle contacts. In general, the complementary results and analyses presented here show that hydration inhibition in cement is correlated with the compositions and structures of the saccharide or degradation species that lead to different adsorption behaviors at hydrating cement surfaces.

\section{CONCLUSIONS}

The very different hydration behaviors of glucose, maltodextrin, and sucrose in cement slurries have been shown to be influenced by their alkaline stabilities, adsorption selectivities for different silicate or aluminate surfaces, and binding strengths at those surfaces. By using advanced solid-state NMR spectroscopy techniques, the transformations and adsorption 
behaviors of mono-, di-, and polysaccharide species in alkaline solutions and at heterogeneous cement surfaces have been determined. Single-pulse solution- and solid-state ${ }^{13} \mathrm{C}$ NMR measurements establish that glucose completely degrades in aqueous cement slurries at early hydration times to form a mixture of saccharinic and other carboxylic acids. In contrast, maltodextrin partially degrades and sucrose remains intact. Pseudoequilibrium adsorption isotherms constructed from quantitative solution-state ${ }^{1} \mathrm{H}$ NMR measurements indicate that, in contrast to glucose, sucrose molecules can adsorb at cement particle surfaces in multiple layers. Multilayer sucrose adsorption is promoted by complexation with $\mathrm{Ca}^{2+}$ cations at surface sites, where the dissolution of surface ions leads to increased local $\mathrm{Ca}^{2+}$ concentrations. The different adsorption behaviors of glucose, its degradation products, maltodextrin, and sucrose have been shown to be directly related to their molecular structures and solution-state reactivities that lead to different binding characteristics at cement particle surfaces. Two-dimensional ${ }^{13} \mathrm{C}\left\{{ }^{1} \mathrm{H}\right\}$ HETCOR NMR spectra of hydrated white Portland and gray oilwell cements establish that glucose degradation species interact strongly, but nonselectively, with aluminate hydration products and suggest the selective adsorption of sucrose at nonhydrated tricalcium silicate surface sites. These results indicate that the preferential adsorption of saccharide species at initially nonhydrated tricalcium silicate surface sites leads to the delayed formation of calcium silicate hydrates and consequently more effective inhibition of cement hydration.

Importantly, the distinct reaction and surface-interaction properties of the saccharides and their degradation products lead to adsorbed organic species that compete very differently with water at heterogeneous cement particle surfaces. Their diverse adsorption properties correlate with and account for the significantly different influences that the saccharides have on cement hydration. The advanced NMR techniques demonstrated here provide new details into the mechanisms of saccharide-mediated cement hydration that are expected to be broadly applicable to systems where the interactions of organic species at heterogeneous aluminate, silicate, or aluminosilicate surfaces play important roles. Such measurements yield insights that can be used to establish molecular criteria for the design or selection of saccharide species aimed at controlling hydration, corrosion, adhesion, or related surface phenomena.

\section{ASSOCIATED CONTENT}

\section{S Supporting Information}

X-ray fluorescence and Rietveld analyses of nonhydrated gray oilwell and white Portland cement. Description of protocols for quantitative analyses of the single-pulse (direct excitation) ${ }^{1} \mathrm{H}$, ${ }^{13} \mathrm{C}$, ${ }^{27} \mathrm{Al}$, and ${ }^{29} \mathrm{Si}$ NMR spectra used to determine relative populations of different ${ }^{1} \mathrm{H},{ }^{13} \mathrm{C},{ }^{27} \mathrm{Al}$, and ${ }^{29} \mathrm{Si}$ species. Solution-state single-pulse ${ }^{1} \mathrm{H}$ and ${ }^{13} \mathrm{C}$ NMR spectra of gray oilwell cement slurry extracts. Solid-state $1 \mathrm{D}$ single-pulse ${ }^{27} \mathrm{Al}$ and ${ }^{29} \mathrm{Si}$ MAS NMR spectra of hydrated white Portland and gray oilwell cements. Solid-state $2 \mathrm{D}{ }^{13} \mathrm{C}\left\{{ }^{1} \mathrm{H}\right\}$ HETCOR NMR spectra of hydrated gray oilwell cement in the presence of glucose and sucrose. This material is available free of charge via the Internet at http://pubs.acs.org.

\section{AUTHOR INFORMATION}

Notes

The authors declare no competing financial interest.

\section{ACKNOWLEDGMENTS}

This work was supported by a grant from Halliburton, Inc. The NMR experiments were conducted using the Central Facilities of the UCSB Materials Research Laboratory supported by the MRSEC program of the U.S. National Science Foundation under award no. DMR-1121053 and the California NanoSystems Institute. The NMR measurements at $18.8 \mathrm{~T}$ were conducted using an NMR spectrometer acquired with funding support from the U.S. National Institutes of Health (grant no. 1S10 RR019899). The MRL Central Facilities are a member of the NSF-funded Materials Research Facilities Network (www. mrfn.org).

\section{REFERENCES}

(1) Wang, D. B.; Wallace, A. F.; De Yoreo, J. J.; Dove, P. M. Carboxylated molecules regulate magnesium content of amorphous calcium carbonates during calcification. Proc. Natl. Acad. Sci. U.S.A. 2009, 106, 21511-21516.

(2) Smith, J. V. Biochemical evolution. I. Polymerization on internal, organophilic silica surfaces of dealuminated zeolites and feldspars. Proc. Natl. Acad. Sci. U.S.A. 1998, 95, 3370-3375.

(3) Parsons, I.; Lee, M. R.; Smith, J. V. Biochemical evolution II: Origin of life in tubular microstructures on weathered feldspar surfaces. Proc. Natl. Acad. Sci. U.S.A. 1998, 95, 15173-15176.

(4) Lambert, J. B.; Gurusamy-Thangavelu, S. A.; Ma, K. B. A. The silicate-mediated formose reaction: bottom-up synthesis of sugar silicates. Science 2010, 327, 984-986.

(5) Liu, J. Z.; Wang, S. Q.; Zhang, P.; Said-Al-Naief, N.; Michalek, S. M.; Feng, X. Molecular mechanism of the bifunctional role of lipopolysaccharide in osteoclastogenesis. J. Biol. Chem. 2009, 284, $12512-12523$.

(6) Chheda, J. N.; Huber, G. W.; Dumesic, J. A. Liquid-phase catalytic processing of biomass-derived oxygenated hydrocarbons to fuels and chemicals. Angew. Chem., Int. Ed. 2007, 46, 7164-7183.

(7) Raja, P. B.; Sethuraman, M. G. Natural products as corrosion inhibitor for metals in corrosive media - a review. Mater. Lett. 2008, 62, $113-116$.

(8) Zhang, J.; Weissinger, E. A.; Peethamparan, S.; Scherer, G. W. Early hydration and setting of oil well cement. Cem. Concr. Res. 2010, 40, 1023-1033.

(9) Bullard, J. W.; Jennings, H. M.; Livingston, R. A.; Nonat, A.; Scherer, G. W.; Schweitzer, J. S.; Scrivener, K. L.; Thomas, J. J. Mechanisms of cement hydration. Cem. Concr. Res. 2011, 41, 12081223.

(10) Smith, B. J.; Rawal, A.; Funkhouser, G. P.; Roberts, L. R.; Gupta, V.; Israelachvili, J. N.; Chmelka, B. F. Origins of saccharide-dependent hydration at aluminate, silicate, and aluminosilicate surfaces. Proc. Natl. Acad. Sci. U.S.A. 2011, 108, 8949-8954.

(11) Taylor, H. F. W. Cement Chemistry; Academic Press: London, 1990.

(12) Cheung, J.; Jeknavoriana, A.; Roberts, L.; Silva, D. Impact of admixtures on the hydration kinetics of Portland cement. Cem. Concr. Res. 2011, 41, 1289-1309.

(13) Thomas, N. L.; Birchall, J. D. The retarding action of sugars on cement hydration. Cem. Concr. Res. 1983, 13, 830-842.

(14) Luke, K.; Luke, G. Effect of sucrose on retardation of Portland cement. Adv. Cem. Res. 2000, 12, 9-18.

(15) Zhang, L. H.; Catalan, L. J. J.; Balec, R. J.; Larsen, A. C.; Esmaeili, H. H.; Kinrade, S. D. Effects of saccharide set retarders on the hydration of ordinary Portland cement and pure tricalcium silicate. J. Am. Ceram. Soc. 2010, 93, 279-287.

(16) Young, J. F. A review of the mechanisms of set-retardation in portland cement pastes containing organic admixtures. Cem. Concr. Res. 1972, 2, 415-433.

(17) Milestone, N. B. Hydration of tricalcium silicate in the presence of lignosulfonates, glucose, and sodium gluconate. J. Am. Ceram. Soc. $1979,62,321-324$. 
(18) Bishop, M.; Barron, A. R. Cement hydration inhibition with sucrose, tartaric acid, and lignosulfonate: Analytical and spectroscopic study. Ind. Eng. Chem. Res. 2006, 45, 7042-7049.

(19) Wang, P.; Xia, P.; Chen, Z. SEM observation of the influence of sucrose and $\mathrm{KOH}$ on formation of sulfoaluminate hydrates of a cement clinker during early hydration. Mater. Res. Soc. Symp. Proc. 1995, 370, 143-147.

(20) Bruere, G. M. Set-retarding effects of sugars in Portland cement pastes. Nature 1966, 212, 502-503.

(21) Previte, R. W. Some insights on the mechanism of saccharide set retardation of Portland cement. Cem. Concr. Res. 1971, 1, 301-316.

(22) Thomas, N. L.; Birchall, J. D. The retarding action of sugars on cement hydration. Cem. Concr. Res. 1983, 13, 830-842.

(23) Ramachandran, V. S.; Lowery, M. S. Conduction calorimetric investigation of the effect of retarders on the hydration of Portland cement. Thermochim. Acta 1992, 195, 373-387.

(24) Peschard, A.; Govin, A.; Grosseau, P.; Guilhot, B.; Guyonnet, R. Effect of polysaccharides on the hydration of cement paste at early ages. Cem. Concr. Res. 2004, 34, 2153-2158.

(25) Skibsted, J.; Hall, C. Characterization of cement minerals, cements and their reaction products at the atomic and nano-scale. Cem. Concr. Res. 2008, 38, 205-225.

(26) Zanni, H.; Rassem-Bertolo, R.; Masse, S.; Fernandez, L.; Nieto, P.; Bresson, B. A spectroscopic NMR investigation of the calcium silicate hydrates present in cement and concrete. Magn. Reson. Imag. 1996, 14, 827-831.

(27) Edwards, C. L.; Alemany, L. B.; Barron, A. R. Solid-state ${ }^{29} \mathrm{Si}$ NMR analysis of cements: comparing different methods of relaxation analysis for determining spin-lattice relaxation times to enable determination of the $\mathrm{C}_{3} \mathrm{~S} / \mathrm{C}_{2} \mathrm{~S}$ ratio. Ind. Eng. Chem. Res. 2007, 46, $5122-5130$

(28) Skibsted, J.; Jakobsen, H. J.; Hall, C. Direct observation of aluminum guest ions in the silicate phases of cement minerals by ${ }^{27} \mathrm{Al}$ MAS NMR spectroscopy. J. Chem. Soc., Faraday Trans. 1994, 90, 2095-2098.

(29) Le Saout, G.; Lecolier, E.; Rivereau, A.; Zanni, H. Chemical structure of cement aged at normal and elevated temperatures and pressures, part II: low permeability class $\mathrm{G}$ oilwell cement. Cem. Concr. Res. 2006, 36, 428-433.

(30) Sun, G. K.; Young, J. F.; Kirkpatrick, R. J. The role of Al in C-S$\mathrm{H}$ : NMR, XRD, and compositional results for precipitated samples. Cem. Concr. Res. 2006, 36, 18-29.

(31) Andersen, M. D.; Jakobsen, H. J.; Skibsted, J. A new aluminiumhydrate species in hydrated Portland cements characterized by ${ }^{27} \mathrm{Al}$ and ${ }^{29} \mathrm{Si}$ MAS NMR spectroscopy. Cem. Concr. Res. 2006, 36, 3-17.

(32) Rawal, A.; Smith, B. J.; Athens, G. L.; Edwards, C. L.; Roberts, L.; Gupta, V.; Chmelka, B. F. Molecular silicate and aluminate species in anhydrous and hydrated cements. J. Am. Chem. Soc. 2010, 132, 7321-7337.

(33) Janicke, M. T.; Landry, C. C.; Christiansen, S. C.; Birtalan, S.; Stucky, G. D.; Chmelka, B. F. Low silica MCM-41 composites and mesoporous solids. Chem. Mater. 1999, 11, 1342-1351.

(34) Hunger, M. Multinuclear solid-state NMR studies of acidic and non-acidic hydroxyl protons in zeolites. Solid State Nucl. Magn. Reson. 1996, 6, 1-29.

(35) Patt, S. L.; Shoolery, J. N. Attached proton test for ${ }^{13} \mathrm{C}$ NMR. J. Magn. Reson. 1982, 46, 535-539.

(36) King, T. C.; Dobson, C. M.; Rodger, S. A. Hydration of tricalcium silicate with $\mathrm{D}_{2} \mathrm{O}$. J. Mater. Sci. Lett. 1988, 7, 861-863.

(37) Chmelka, B. F.; Zwanziger, J. W. In NMR Basic Principles and Progress; Kosfeld, P., Blümich, B., Eds.; Springer-Verlag: Berlin, 1994; Vol. 33, pp 79-124.

(38) Yang, B. Y.; Montgomery, R. Alkaline degradation of glucose: effect of initial concentration of reactants. Carbohydr. Res. 1996, 280, $27-45$.

(39) Ellis, A. V.; Wilson, M. A. Carbon exchange in hot alkaline degradation of glucose. J. Org. Chem. 2002, 67, 8469-8474.
(40) de Bruijn, J. M.; Touwslager, F.; Kieboom, A. P. G.; van Bekkum, H. Alkaline degradation of monosaccharides. Starch 1987, 39, $49-52$.

(41) Bagno, A.; Rastrelli, F.; Saielli, G. Prediction of the ${ }^{1} \mathrm{H}$ and ${ }^{13} \mathrm{C}$ NMR spectra of $\alpha$-D-glucose in water by DFT methods and MD simulations. J. Org. Chem. 2007, 72, 7373-7381.

(42) Comotti, M.; Della Pina, C.; Rossi, M. Mono- and bimetallic catalysts for glucose oxidation. J. Mol. Catal. A: Chem. 2006, 251, 8992.

(43) Onda, A.; Ochi, T.; Kajiyoshi, K.; Yanagisawa, K. A new chemical process for catalytic conversion of D-glucose into lactic acid and gluconic acid. Appl. Catal., A 2008, 343, 49-54.

(44) Pannetier, N.; Khoukh, A.; Francois, J. Physico-chemical study of sucrose and calcium ions interactions in alkaline aqueous solutions. Macromol. Symp. 2001, 166, 203-208.

(45) Cancilla, M. T.; Penn, S. G.; Lebrilla, C. B. Alkaline degradation of oligosaccharides coupled with matrix-assisted laser desorption/ ionization Fourier transform mass spectrometry: a method for sequencing oligosaccharides. Anal. Chem. 1998, 70, 663-672.

(46) Young, R. A.; Sarkanen, K. V. Use of alkaline degradation for structural characterization of branched-chained polysaccharides. Carbohydr. Res. 1977, 59, 193-201.

(47) The rate of cement hydration with $\mathrm{D}_{2} \mathrm{O}$ is slower by a factor of approximately 3 compared to $\mathrm{H}_{2} \mathrm{O}$, resulting in proportionally lower quantities of hydration products being formed at short times.

(48) Paria, S.; Khilar, K. C. A review on experimental studies of surfactant adsorption at the hydrophilic solid-water interface. Adv. Colloid Interface Sci. 2004, 110, 75-95.

(49) Parida, S. K.; Dash, S.; Patel, S.; Mishra, B. K. Adsorption of organic molecules on silica surface. Adv. Colloid Interface Sci. 2006, $121,77-110$.

(50) Limousin, G.; Gaudet, J. P.; Charlet, L.; Szenknect, S.; Barthes, V.; Krimissa, M. Sorption isotherms: a review on physical bases, modeling and measurement. Appl. Geochem. 2007, 22, 249-275.

(51) Juilland, P.; Gallucci, E.; Flatt, R. Scrivener, K. Dissolution theory applied to the induction period in alite hydration. Cem. Concr. Res. 2010, 40, 831-844.

(52) Bullard, J. W.; Flatt, R. J. New insights into the effect of calcium hydroxide precipitation on the kinetics of tricalcium silicate hydration. J. Am. Ceram. Soc. 2010, 93, 1894-1903.

(53) Jennings, H. M.; Pratt, P. L. Experimental argument for the existence of a protective membrane surrounding Portland cement during the induction period. Cem. Concr. Res. 1979, 9, 501-506.

(54) Stein, H. N.; Stevels, J. M. Influence of silica on hydration of $3 \mathrm{CaO}, \mathrm{SiO}_{2}$. J. Appl. Chem. 1964, 14, 338-346.

(55) Wilkinson, A. P.; Jupe, A. C.; Funkhouser, G. P. Oil-well cement and $\mathrm{C}_{3} \mathrm{~S}$ hydration under high pressure as seen by in situ $\mathrm{X}$-ray diffraction. J. Am. Ceram. Soc. 2011, 94, 1591-1597.

(56) d'Espinose de Lacaillerie, J. B.; Fretigny, C.; Massiot, D. MAS NMR spectra of quadrupolar nuclei in disordered solids: the Czjzek model. J. Magn. Reson. 2008, 192, 244-251.

(57) Shimada, Y.; Young, J. F. Thermal stability of ettringite in alkaline solutions at 80 degrees C. Cem. Concr. Res. 2004, 34, 22612268.

(58) Skibsted, J.; Henderson, E.; Jakobsen, H. J. Characterization of calcium aluminate phases in cements by ${ }^{27} \mathrm{Al}$ MAS NMR spectroscopy. Inorg. Chem. 1993, 32, 1013-1027.

(59) Christensen, A. N.; Jensen, T. R.; Hanson, J. C. Formation of ettringite, $\mathrm{AFt}$, and monosulfate, $\mathrm{AFm}-14$, in hydrothermal hydration of Portland cement and of calcium aluminum oxide - calcium sulfate dihydrate mixtures studied by in-situ synchrotron X-ray powder diffraction. J. Solid State Chem. 2004, 177, 1944-1951.

(60) Possible contributions from interactions between hydrophobic methyl groups and hydrophilic $-\mathrm{AlOH}$ moieties are not resolved but are expected to be weak. Intramolecular interactions between ${ }^{13} \mathrm{C}-{ }^{1} \mathrm{H}$ species that are not directly bonded give rise to weak correlated intensity in the $2 \mathrm{D}$ spectrum of Figure $4 \mathrm{~b}$ (e.g., between the ${ }^{13} \mathrm{CH}_{3}-\mathrm{C}^{1} \mathrm{HOH}-$ species $\left({ }^{13} \mathrm{C}\right.$ signal at $\left.20 \mathrm{ppm}\right)$ and carbinol protons $\left({ }^{1} \mathrm{H}\right.$ signal at 3.6 $\mathrm{ppm})$, compared to that of directly bonded ${ }^{13} \mathrm{C}-{ }^{1} \mathrm{H}$ moieties that are 
strongly coupled and yield strong $2 \mathrm{D}$ intensity correlations. It is reasonable to expect similarly weak intramolecular ${ }^{13} \mathrm{C}-{ }^{1} \mathrm{H}$ interactions between the $-{ }^{13} \mathrm{CHOH}-(\sim 70 \mathrm{ppm})$ and $-\mathrm{CH}_{3}$ proton (1 $\mathrm{ppm})$ moieties. Intramolecular interactions for more distant ${ }^{13} \mathrm{C}-{ }^{1} \mathrm{H}$ spin pairs will be even weaker and are not likely to be detected, consistent with the absence of a correlated intensity between $-{ }^{13} \mathrm{COO}^{-}-(\sim 184 \mathrm{ppm})$ and $-\mathrm{CH}_{3}-{ }^{1} \mathrm{H}$ species (1 ppm); this also appears to rule out the presence of small carboxylic acids (e.g., acetic acid, $\mathrm{CH}_{3} \mathrm{COO}^{-}$, or related species with $-{ }^{13} \mathrm{COO}^{-}$and methyl groups in close proximity) among glucose degradation products. Nevertheless, the 2D ${ }^{13} \mathrm{C}\left\{{ }^{1} \mathrm{H}\right\}$ HETCOR spectrum in Figure $4 \mathrm{~b}$ exhibits strong intensity correlations for both the $-{ }^{13} \mathrm{CHOH}-(\sim 70$ $\mathrm{ppm})$ and $-{ }^{13} \mathrm{COO}^{-}(\sim 184 \mathrm{ppm})$ species with ${ }^{1} \mathrm{H}$ species at $1 \mathrm{ppm}$ that are much stronger than those associated with intramolecular ${ }^{13} \mathrm{C}-{ }^{1} \mathrm{H}$ interactions. These strong correlated signal intensities are thus consistent with contributions principally from $-\mathrm{AlOH}$ protons, compared to those from $-\mathrm{CH}_{3}$ protons, and reflect the close proximities of the $-\mathrm{CHOH}-$ and $-\mathrm{COO}^{-}$moieties to aluminate surfaces.

(61) Giraudeau, C.; d'Espinose de Lacaillerie, J. B.; Souguir, Z.; Nonat, A.; Flatt, R. J. Surface and intercalation chemistry of polycarboxylate copolymers in cementitious systems. J. Am. Ceram. Soc. 2009, 92, 2471-2488.

(62) Plank, J.; Zhimin, D.; Keller, H.; Von Hossle, F.; Seidl, W. Fundamental mechanisms for polycarboxylate intercalation into $\mathrm{C}_{3} \mathrm{~A}$ hydrate phases and the role of sulfate present in cement. Cem. Concr. Res. 2010, 40, 45-57.

(63) Angyal, S. J. Complexes of metal cations with carboydrates in solution. Chem. Soc. Rev. 1980, 9, 415-428.

(64) Bellmann, F.; Damidot, D.; Moser, B.; Skibsted, J. Improved evidence for the existence of an intermediate phase during hydration of tricalcium silicate. Cem. Concr. Res. 2010, 40, 875-884. 


\section{Supporting Information}

Table S1. X-ray fluorescence elemental analyses of the non-hydrated white Portland and grey oilwell cements used in this study.

\begin{tabular}{|c|c|c|}
\hline Analyte & $\begin{array}{l}\text { white Portland } \\
\text { cement } \\
\text { (wt\%) }\end{array}$ & $\begin{array}{c}\text { grey oilwell } \\
\text { cement } \\
\text { (wt \%) }\end{array}$ \\
\hline $\mathrm{SiO}_{2}$ & 24.00 & 20.90 \\
\hline $\mathrm{Al}_{2} \mathrm{O}_{3}$ & 2.00 & 3.00 \\
\hline $\mathrm{Fe}_{2} \mathrm{O}_{3}$ & 0.35 & 4.30 \\
\hline $\mathrm{CaO}$ & 67.00 & 63.50 \\
\hline $\mathrm{MgO}$ & 0.58 & 3.30 \\
\hline $\mathrm{SO}_{3}$ & 2.00 & 2.80 \\
\hline $\mathrm{Na}_{2} \mathrm{O}$ & 0.17 & 0.09 \\
\hline $\mathrm{K}_{2} \mathrm{O}$ & 0.05 & 0.27 \\
\hline $\mathrm{TiO}_{2}$ & 0.08 & 0.19 \\
\hline $\mathrm{P}_{2} \mathrm{O}_{5}$ & 0.37 & 0.09 \\
\hline $\mathrm{Mn}_{2} \mathrm{O}_{3}$ & 0.02 & 0.06 \\
\hline $\mathrm{SrO}$ & 0.13 & 0.10 \\
\hline $\mathrm{Cr}_{2} \mathrm{O}_{3}$ & $<0.01$ & 0.02 \\
\hline $\mathrm{ZnO}$ & $<0.01$ & 0.03 \\
\hline L.O.I. $^{\mathrm{a}}\left(950^{\circ} \mathrm{C}\right)$ & 1.90 & 1.00 \\
\hline Total & 98.65 & 99.65 \\
\hline
\end{tabular}

Table S2: Rietveld analyses of X-ray diffraction patterns acquired for non-hydrated white Portland and grey oilwell cements.

\begin{tabular}{|c|c|c|}
\hline Component & white Portland cement (wt\%) & grey oilwell cement (wt\%) \\
\hline $\mathrm{CaSO}_{4}$ & $2.2( \pm 0.2)$ & $3.2( \pm 0.1)$ \\
\hline $\mathrm{CaCO}_{3}$ & $\mathrm{n} / \mathrm{a}$ & $0.3( \pm 0.2)$ \\
\hline $\mathrm{MgO}$ & $\mathrm{n} / \mathrm{a}$ & $2.3( \pm 0.1)$ \\
\hline $\mathrm{C}_{3} \mathrm{~A}$ (cubic) & $4.1( \pm 0.1)$ & n/a \\
\hline $\mathrm{C}_{4} \mathrm{AF}$ & $\mathrm{n} / \mathrm{a}$ & $16.0( \pm 0.4)$ \\
\hline $\mathrm{C}_{2} \mathrm{~S}$ & $27.9( \pm 0.9)$ & $16.1( \pm 0.1)$ \\
\hline $\mathrm{C}_{3} \mathrm{~S}$ (triclinic) & $3.3( \pm 0.5)$ & $10.9( \pm 0.9)$ \\
\hline $\mathrm{C}_{3} \mathrm{~S}$ (monoclinic) & $62.3( \pm 1.4)$ & $49.9( \pm 1.3)$ \\
\hline
\end{tabular}



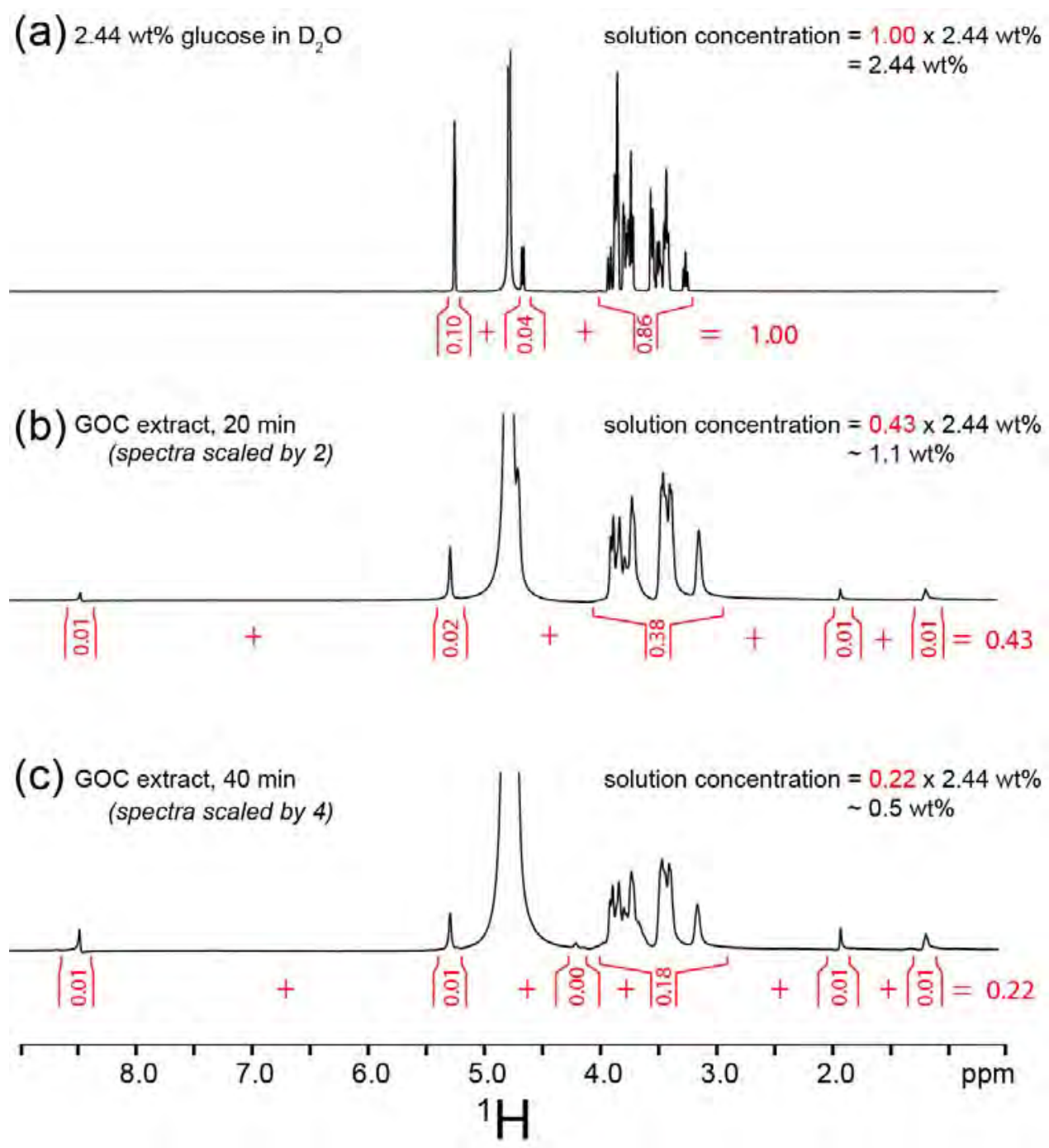

Figure S1: Solution-state ${ }^{1} \mathrm{H}$ NMR spectra of (a) 2.44 wt\% glucose in $\mathrm{D}_{2} \mathrm{O}$, and (b,c) solutions extracted from grey oilwell cement slurries initially containing $1.25 \%$ glucose by weight of cement $\left(\mathrm{D}_{2} \mathrm{O} /\right.$ cement $\left.=0.50\right)$ hydrated in $\mathrm{D}_{2} \mathrm{O}$ at $65{ }^{\circ} \mathrm{C}$ after (b) $20 \mathrm{~min}$ and (c) $40 \mathrm{~min}$. Quantitative analyses of the relative populations of ${ }^{1} \mathrm{H}$ organic species in the cement slurry extract solutions were obtained by integrating the resolved ${ }^{1} \mathrm{H}$ NMR signals, neglecting contributions from residual $\mathrm{H}_{2} \mathrm{O}$ (at $4.7 \mathrm{ppm}$ ). Normalizing the total integrated intensities from all of the other resolved ${ }^{1} \mathrm{H}$ signals (shown in red) in the cement extract solution, relative to the total ${ }^{1} \mathrm{H}$ signal intensity of the known $\mathrm{D}_{2} \mathrm{O}$-saccharide solution (2.44 wt\%), allows the total concentration of organic species in the cement extract solutions to be obtained. The quantity of adsorbed organic species is determined using a simple mass balance. 


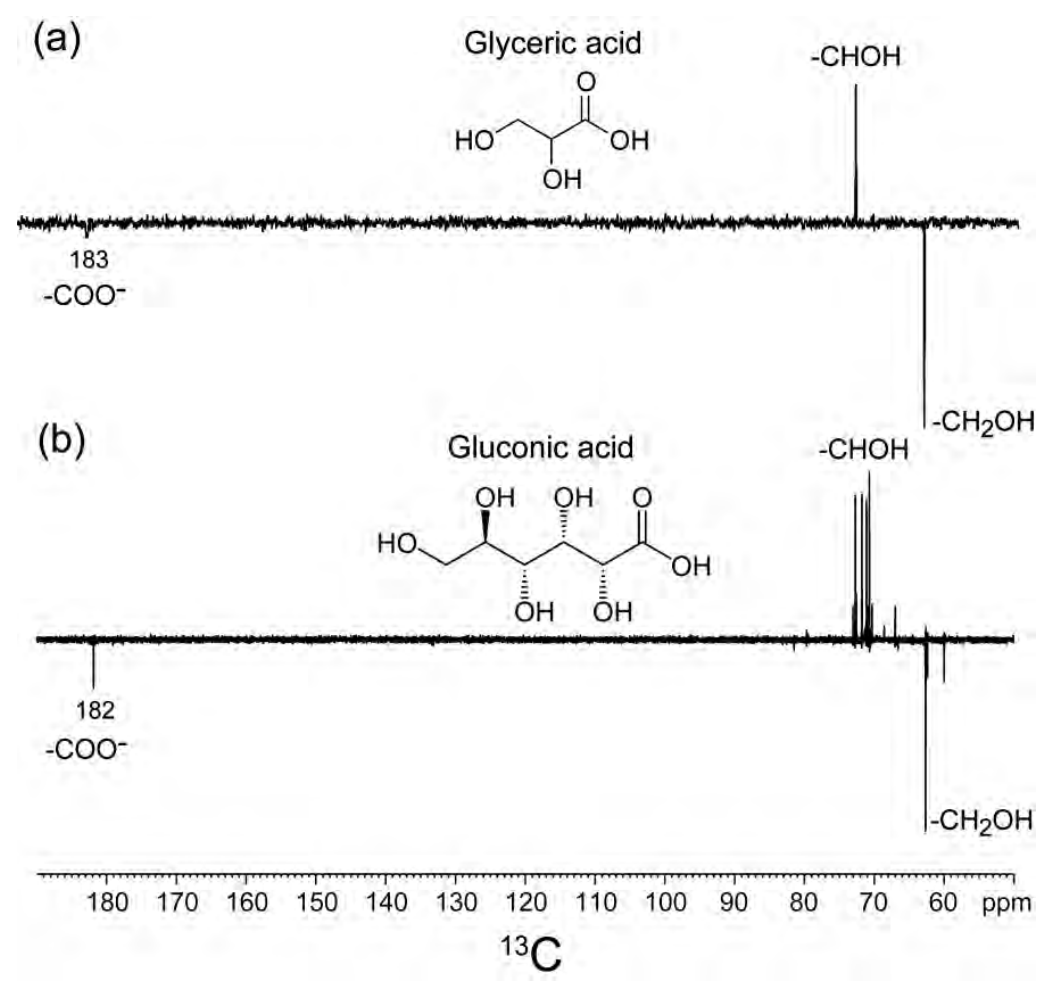

Figure S2: Solution-state ${ }^{13} \mathrm{C}$ APT NMR spectra of $5 \mathrm{wt} \%$ solutions of (a) glyceric acid and (b) gluconic acid added to aqueous solutions extracted from grey oilwell cement slurries after $2 \mathrm{~h}$ at $65{ }^{\circ} \mathrm{C}$. Carboxylic acid species were added to cement extracts to simulate aqueous solution conditions (e.g., $\mathrm{pH}$, cation species) in cement slurries. 


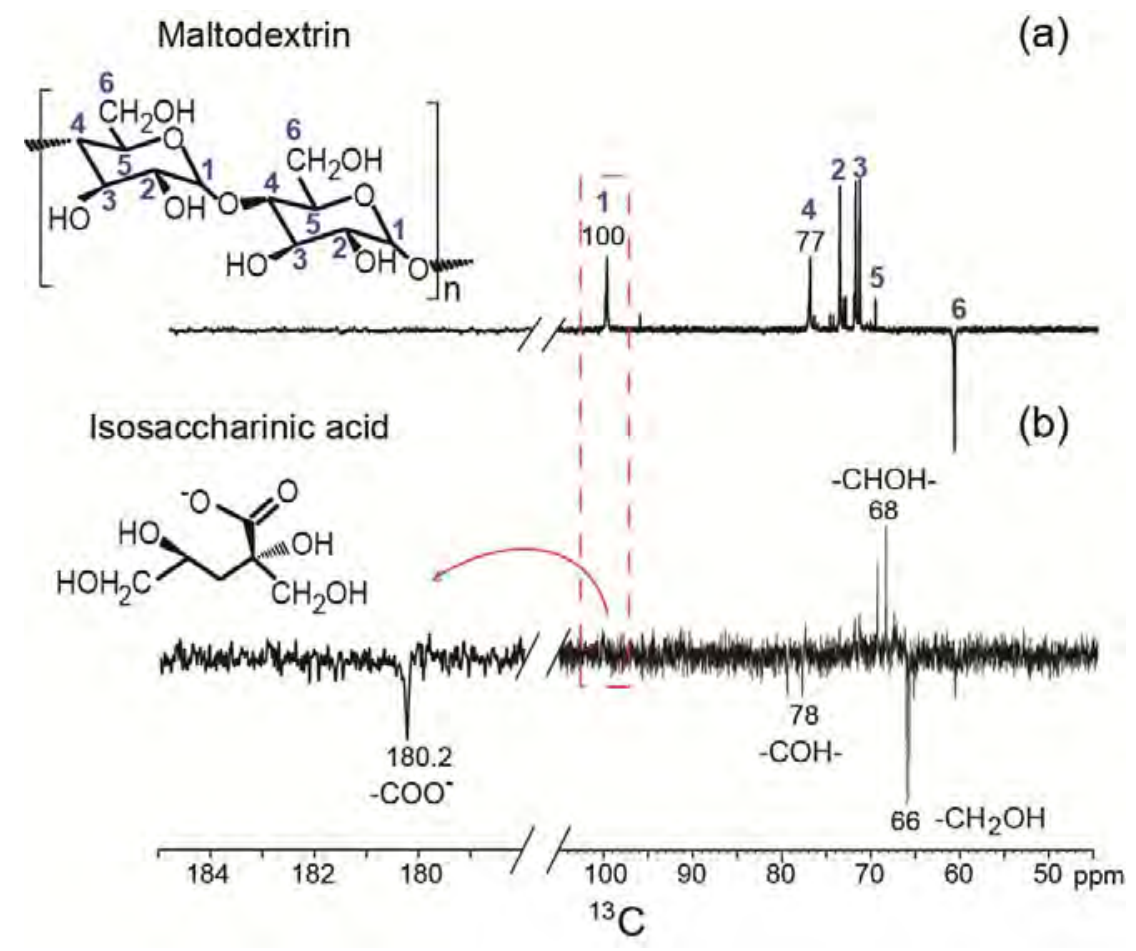

Figure S3. Solution-state ${ }^{13} \mathrm{C}$ APT NMR spectra acquired at $25{ }^{\circ} \mathrm{C}$ of (a) a 5 wt\% maltodextrin solution at $\mathrm{pH} 7$; and (b) an aqueous solution extracted from a grey oilwell cement slurry hydrated for $2 \mathrm{~h}$ at $65{ }^{\circ} \mathrm{C}$ that initially contained $1 \%$ maltodextrin bwoc. The ${ }^{13} \mathrm{C}$ APT NMR spectrum of aqueous cement extract originally containing 1\% maltodextrin bwoc exhibits a new signal at $180.2 \mathrm{ppm}$ assigned to carboxylic acid species, along with signals at approximately 78, 68, and 66 ppm from $-\mathrm{COH}-,-\mathrm{CHOH}^{-}$, and $-\mathrm{CH}_{2} \mathrm{OH}$ moieties, respectively. Such signals are consistent with the structure of glucoisosaccharinic acid (Fig. 2b, inset). No intensity is observed at 100 or 77 ppm from the $C 1$ and $C 4$ moieties, indicating that chemical species with $C 1-\mathrm{O}-C 4$ linkages are not present in detectable quantities in solution and suggesting that only monosaccharides or lower molecular-weight species remain in solution. 

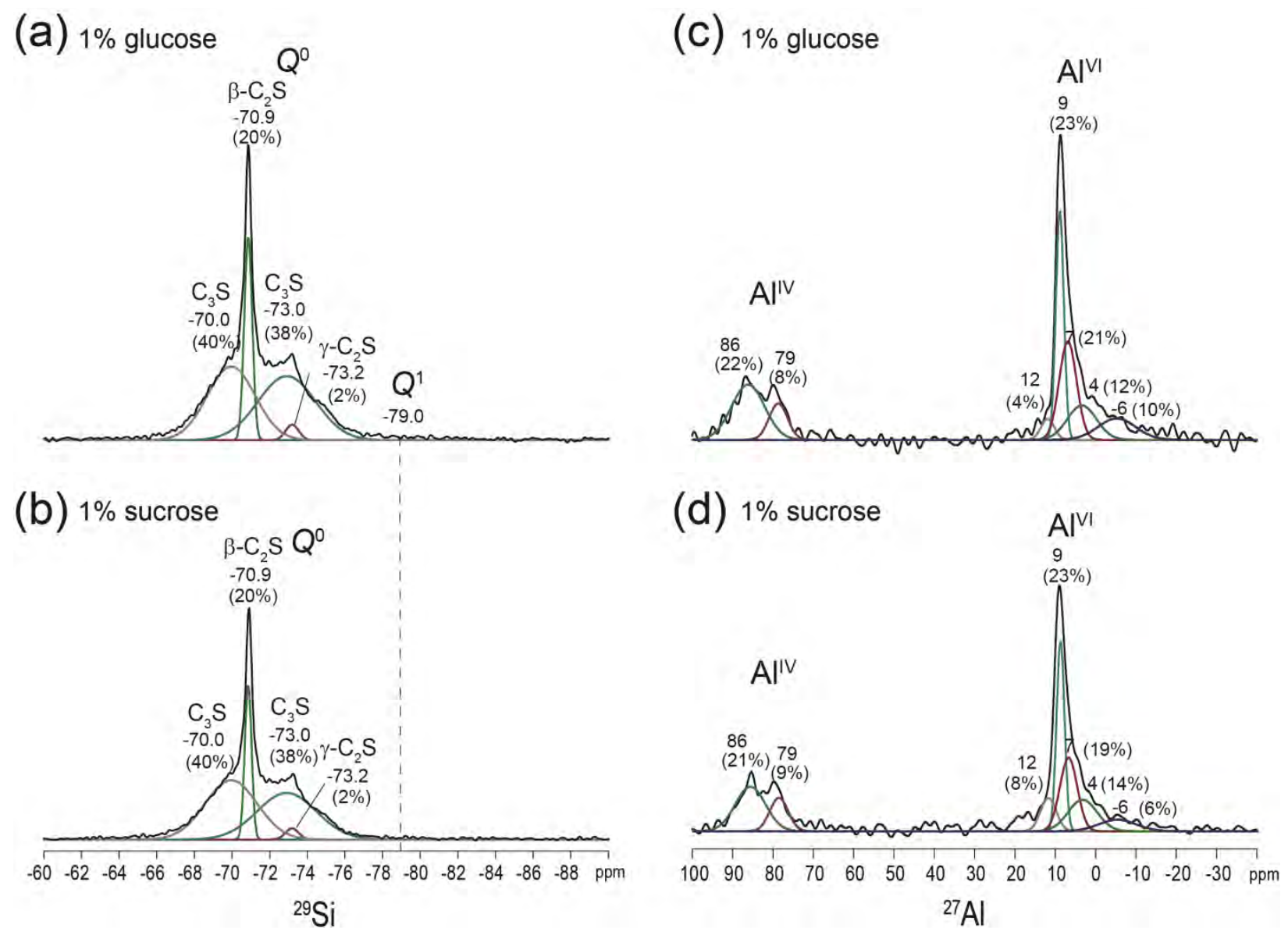

Figure S4: (a,b) Solid-state $1 \mathrm{D}$ single-pulse ${ }^{29}$ Si MAS NMR spectra acquired at $11.7 \mathrm{~T}, 25{ }^{\circ} \mathrm{C}$, $10 \mathrm{kHz}$ MAS for hydrated white Portland cement (4 h, $95{ }^{\circ} \mathrm{C}$ ) with (a) $1 \%$ glucose or (b) $1 \%$ sucrose by weight of cement (bwoc). (c,d) Solid-state 1D single-pulse ${ }^{27}$ Al MAS NMR spectra acquired at $18.8 \mathrm{~T}, 25^{\circ} \mathrm{C}, 20 \mathrm{kHz}$ MAS for hydrated white Portland cement (4 h, $\left.95{ }^{\circ} \mathrm{C}\right)$ with (c) $1 \%$ glucose or (d) $1 \%$ sucrose by weight of cement. The quantities of the different non-hydrated and hydrated silicate and aluminate cement components are shown in parentheses along with their associated peak positions. 
(a) $1 \%$ glucose

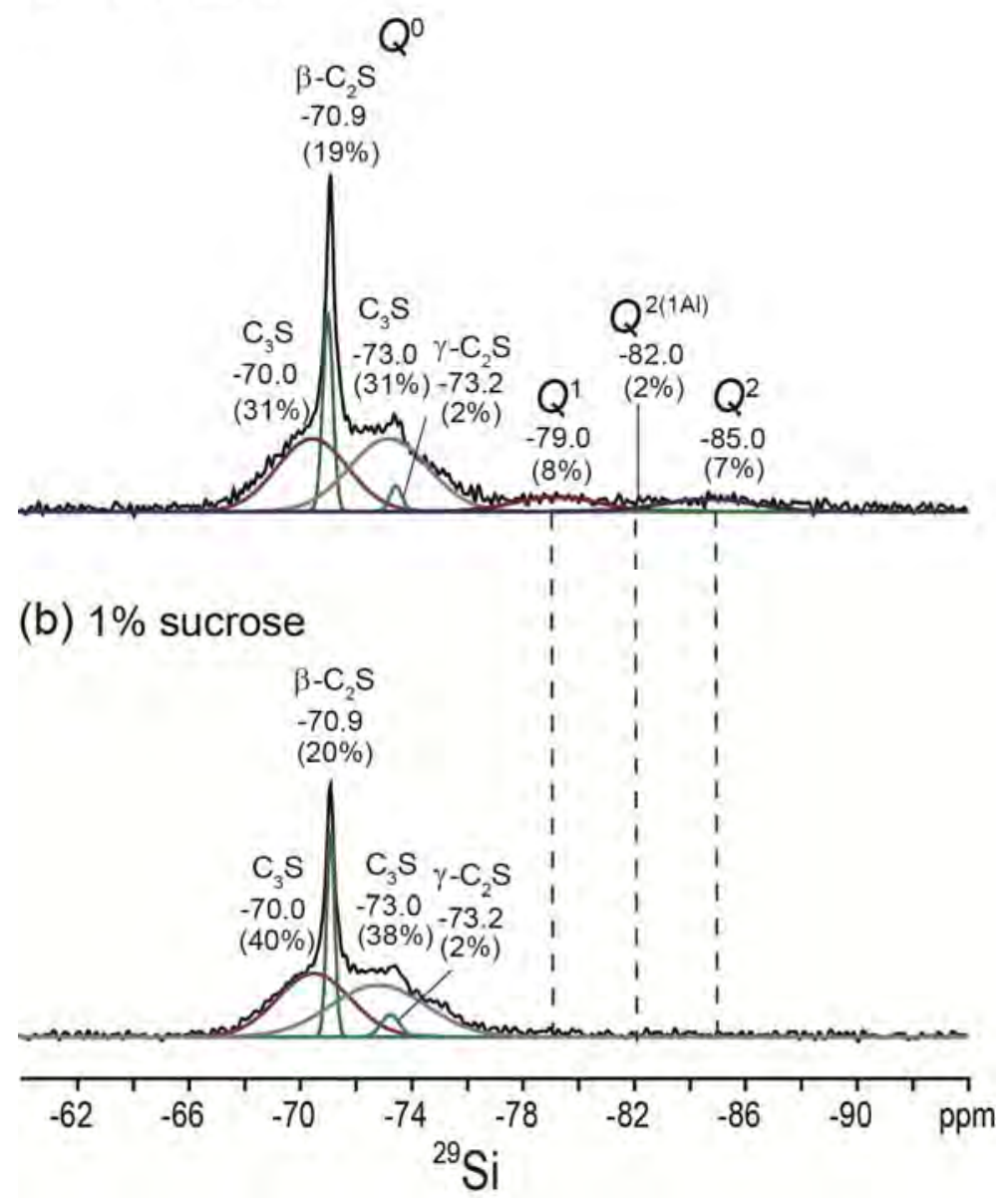

Figure S5: Solid-state 1D single-pulse ${ }^{29} \mathrm{Si}$ MAS NMR spectra acquired at $11.7 \mathrm{~T}, 25{ }^{\circ} \mathrm{C}, 10$ kHz MAS for hydrated white Portland cement $\left(8 \mathrm{~h}, 95{ }^{\circ} \mathrm{C}\right.$ ) with (a) $1 \%$ glucose or (b) $1 \%$ sucrose by weight of cement (bwoc). The quantities of the different non-hydrated and hydrated silicate cement components are shown in parentheses along with their associated isotropic chemical shifts. 


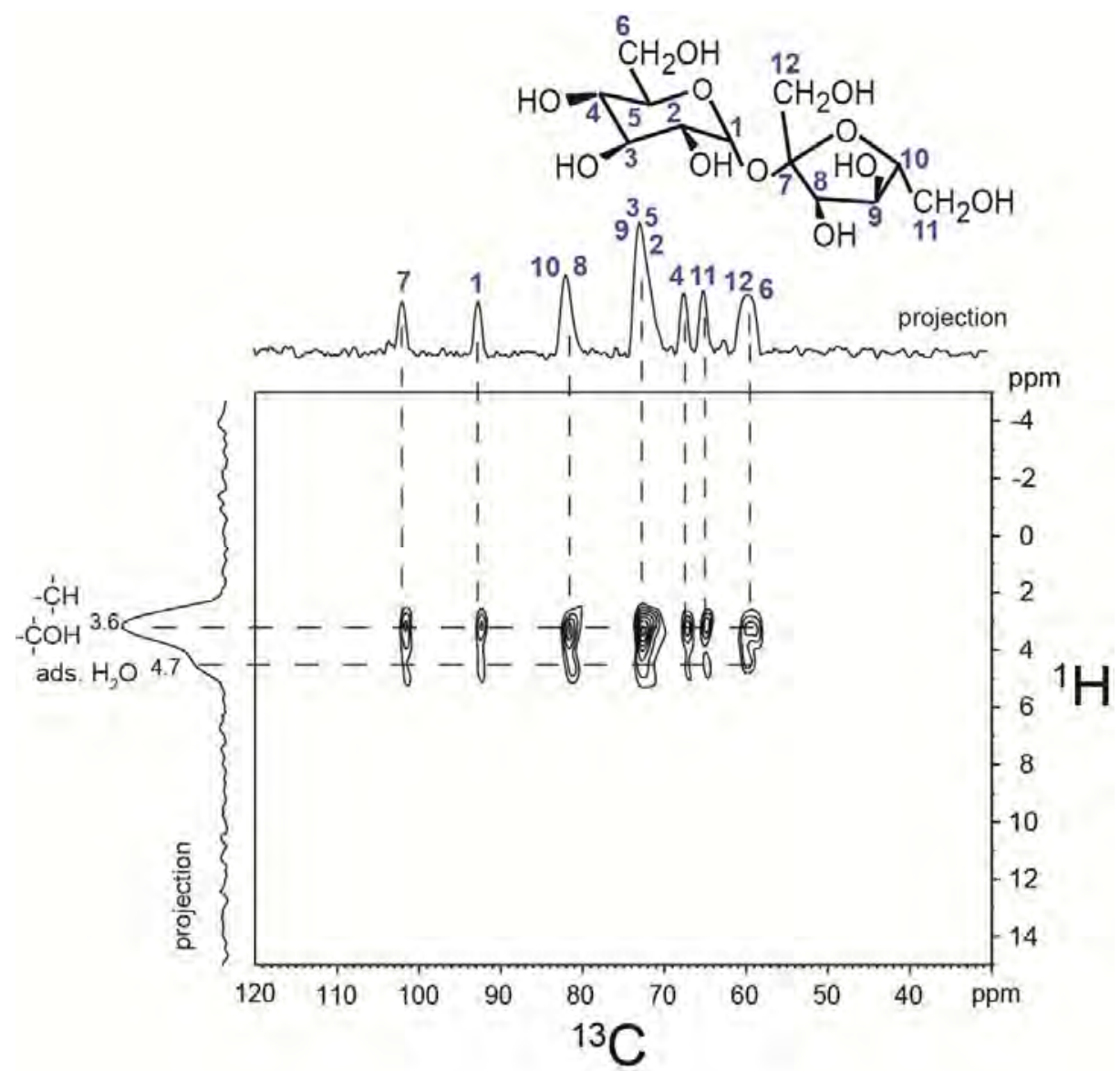

Figure S6: Solid-state $2 \mathrm{D}{ }^{13} \mathrm{C}\left\{{ }^{1} \mathrm{H}\right\}$ HETCOR NMR spectrum acquired at $11.7 \mathrm{~T}, 25{ }^{\circ} \mathrm{C}, 10 \mathrm{kHz}$ MAS for crystalline sucrose. Overall signal intensity in the ${ }^{13} \mathrm{C}$ and ${ }^{1} \mathrm{H}$ dimensions are projected along their respective axes. 


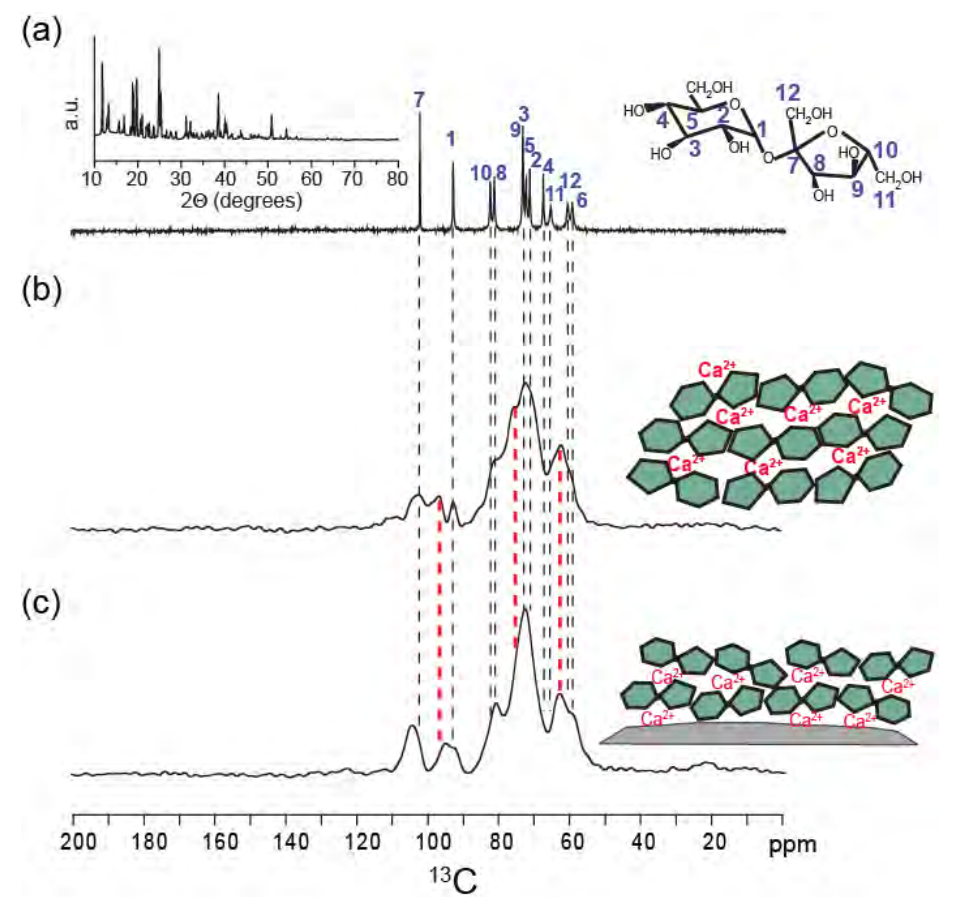

Figure S7: Solid-state 1D single-pulse ${ }^{13} \mathrm{C}$ MAS NMR spectra acquired at $18.8 \mathrm{~T}, 25{ }^{\circ} \mathrm{C}, 10 \mathrm{kHz}$ MAS for (a) crystalline sucrose, (b) sucrose- $\mathrm{Ca}^{2+}$ powder (molar ratio 1.25 sucrose : $1 \mathrm{Ca}^{2+}$ ) precipitated from a $1 \mathrm{wt} \%$ solution of sucrose in saturated $\mathrm{Ca}(\mathrm{OH})_{2}$ at $95{ }^{\circ} \mathrm{C}$, and (c) hydrated white Portland cement $\left(4 \mathrm{~h}, 95{ }^{\circ} \mathrm{C}\right)$ with $1 \%$ sucrose $\left(99 \%{ }^{13} \mathrm{C}\right.$-labeled) by weight of cement. The dotted black lines correspond to the isotropic ${ }^{13} \mathrm{C}$ chemical shifts of distinct ${ }^{13} \mathrm{C}$ moieties in sucrose and are assigned as shown in Figure S7a. As shown in Figure S7b, the solid-state ${ }^{13} \mathrm{C}$ MAS spectrum of the neat sucrose- $\mathrm{Ca}^{2+}$ precipitate exhibits ${ }^{13} \mathrm{C}$ signals with similar chemical shifts as for crystalline sucrose, albeit substantially broadened. Compared to crystalline sucrose, additional ${ }^{13} \mathrm{C}$ signal intensity due to sucrose- $\mathrm{Ca}^{2+}$ complexation is observed in the ${ }^{13} \mathrm{C}$ MAS spectrum, as indicated by the dotted red lines. When an organic molecule interacts with inorganic ions, the local electronic environments of nearby ${ }^{13} \mathrm{C}$ species can be altered, leading to changes in their ${ }^{13} \mathrm{C}$ isotropic chemical shifts. The ${ }^{13} \mathrm{C}$ MAS spectrum of hydrated white Portland cement (Figure $7 \mathrm{c}$ ) initially containing $1 \%$ sucrose $\left(99 \%{ }^{13} \mathrm{C}\right.$-labeled) by weight of cement is very similar to that observed for the sucrose- $\mathrm{Ca}^{2+}$ precipitate (Fig. S7b). It is noteworthy that ${ }^{13} \mathrm{C}$ signal intensity associated with sucrose- $\mathrm{Ca}^{2+}$ complexation are also observed in the ${ }^{13} \mathrm{C}$ MAS spectrum of sucrose adsorbed on white Portland cement (dotted red lines). These results establish that the local electronic environments of the ${ }^{13} \mathrm{C}$ species in sucrose adsorbed at cement particle surfaces are similar to those found in the sucrose- $\mathrm{Ca}^{2+}$ precipitate and suggest that sucrose $-\mathrm{Ca}^{2+}$ complexes are formed at particle surfaces in hydrating cements. 

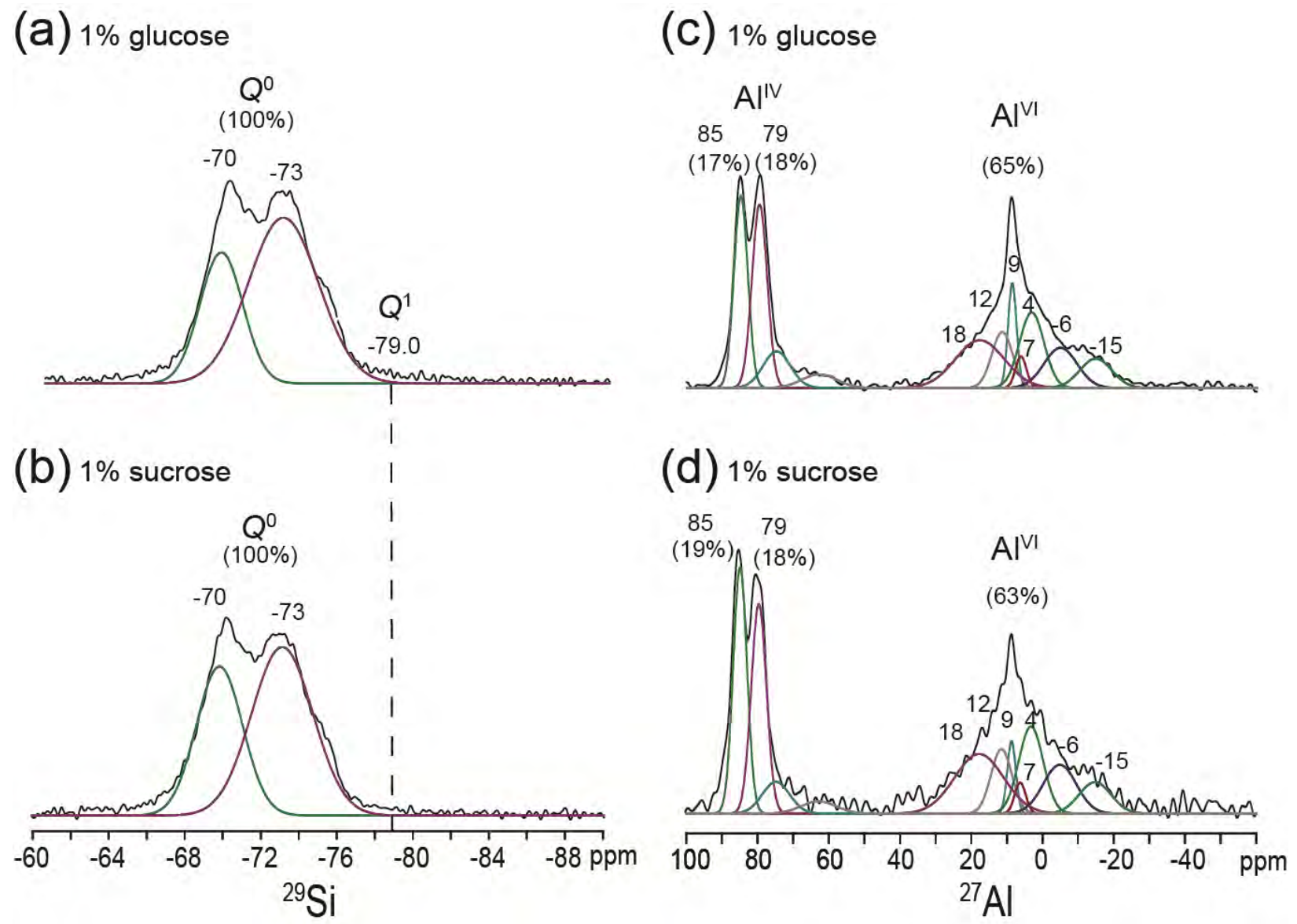

Figure S8: (a,b) Solid-state $1 \mathrm{D}$ single-pulse ${ }^{29}$ Si MAS NMR spectra acquired at $11.7 \mathrm{~T}, 25{ }^{\circ} \mathrm{C}$, $10 \mathrm{kHz}$ MAS for hydrated grey oilwell cement (4 h, $95{ }^{\circ} \mathrm{C}$ ) with (a) $1 \%$ glucose or (b) $1 \%$ sucrose by weight of cement (bwoc). (c,d) Solid-state 1D single-pulse ${ }^{27}$ Al MAS NMR spectra acquired at $18.8 \mathrm{~T}, 25^{\circ} \mathrm{C}, 20 \mathrm{kHz}$ MAS for hydrated grey oilwell cement $\left(4 \mathrm{~h}, 95{ }^{\circ} \mathrm{C}\right)$ with $1 \%$ (c) glucose or (d) sucrose by weight of cement. The quantities of the different non-hydrated and hydrated silicate and aluminate cement components are shown in parentheses along with their associated peak positions. 
(a) $1 \%$ glucose

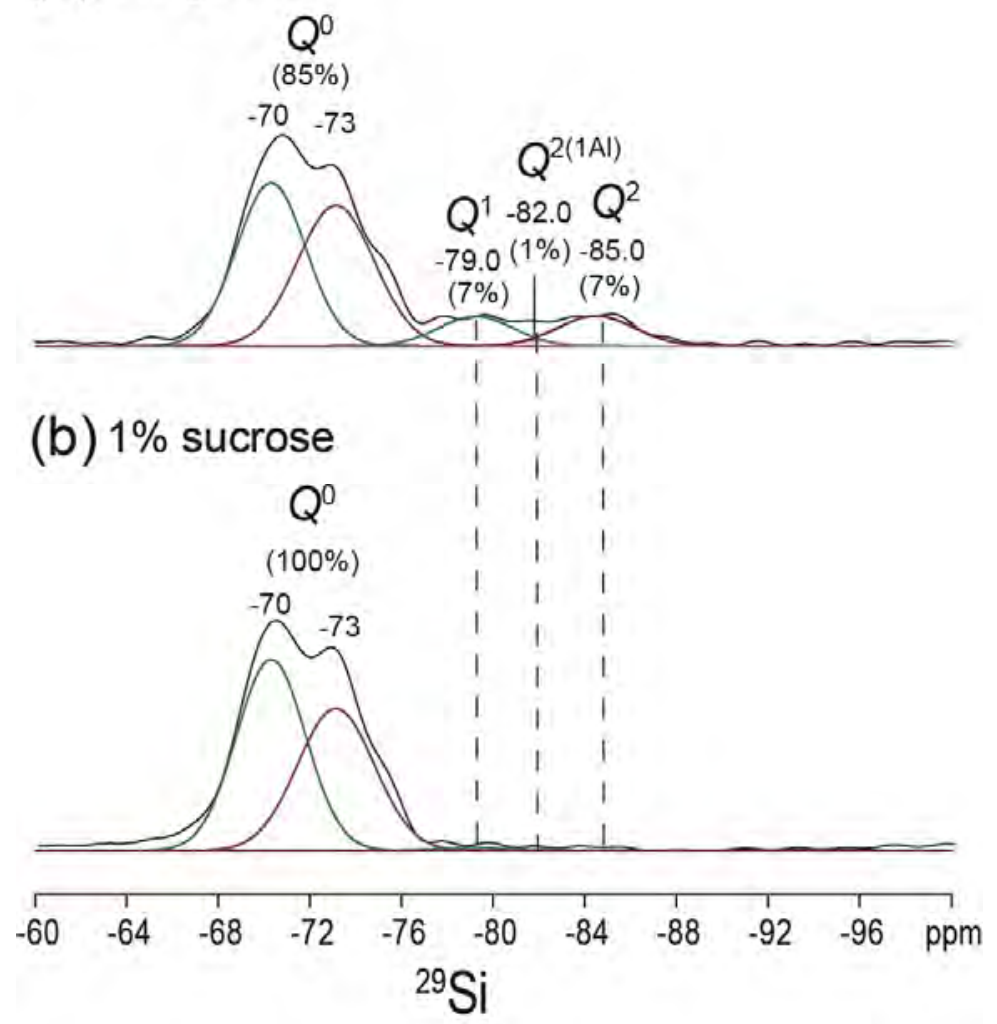

Figure S9: Solid-state $1 \mathrm{D}$ single-pulse ${ }^{29} \mathrm{Si}$ NMR MAS spectra acquired at $11.7 \mathrm{~T}, 25{ }^{\circ} \mathrm{C}, 10$ $\mathrm{kHz}$ MAS for hydrated grey oilwell cement $\left(8 \mathrm{~h}, 95{ }^{\circ} \mathrm{C}\right)$ with (a) $1 \%$ glucose or (b) $1 \%$ sucrose by weight of cement. The quantities of the different non-hydrated and hydrated silicate cement components are shown in parentheses along with their associated isotropic chemical shifts. 
(a) glucose

(b) sucrose
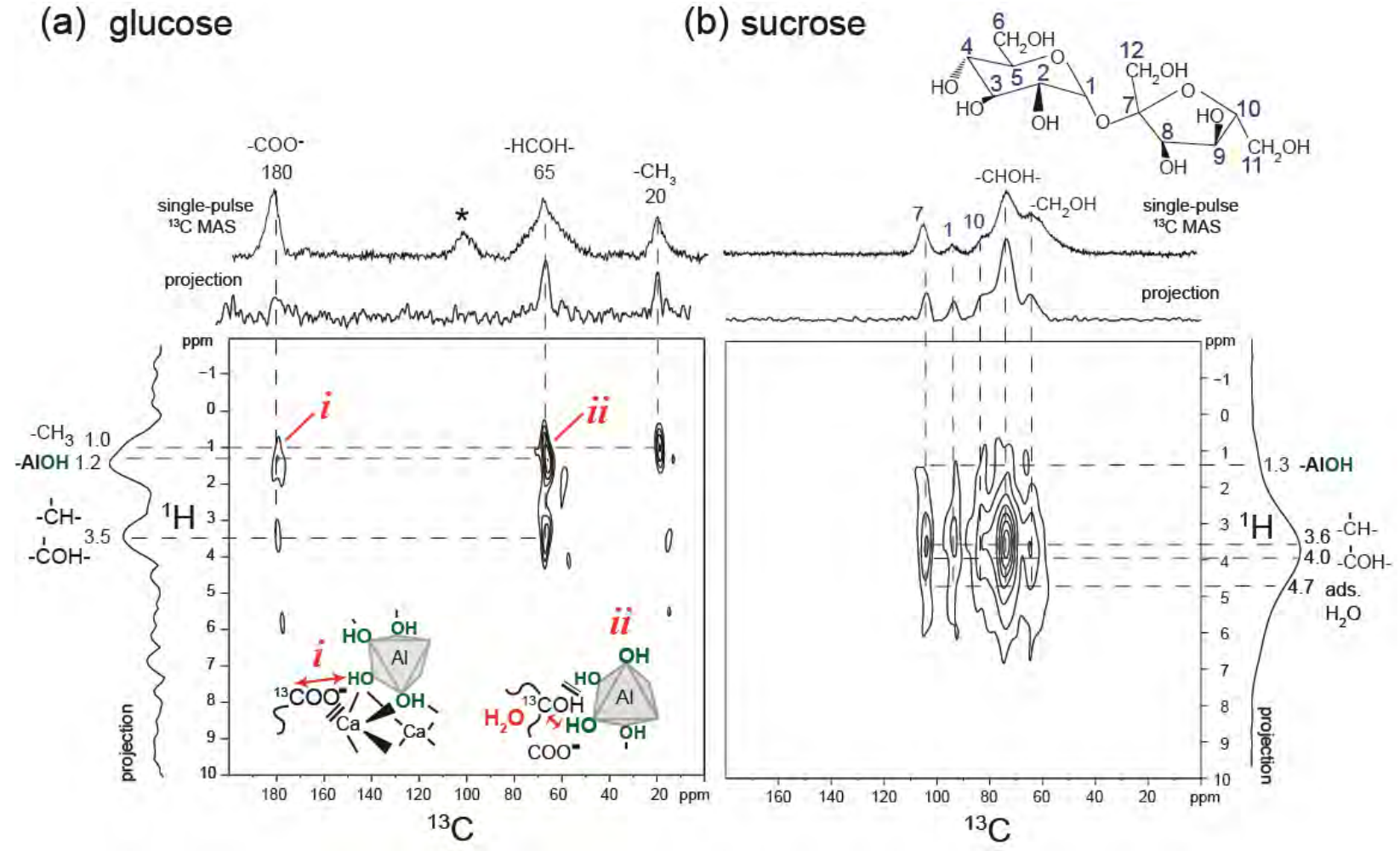

Figure S10. Solid-state 2D ${ }^{13} \mathrm{C}\left\{{ }^{1} \mathrm{H}\right\}$ HETCOR NMR spectra acquired at $11.7 \mathrm{~T}, 25{ }^{\circ} \mathrm{C}, 10 \mathrm{kHz}$ MAS for hydrated grey oilwell cement $\left(4 \mathrm{~h}, 95{ }^{\circ} \mathrm{C}\right)$ and with (a) $1 \%$ glucose $\left(99 \%{ }^{13} \mathrm{C}\right.$-labeled) or (b) $1 \%$ sucrose (99\% ${ }^{13} \mathrm{C}$-labeled) by weight of cement. 1D single-pulse ${ }^{13} \mathrm{C}$ MAS spectra are shown along the horizontal axes for comparison with the 1D projections of the 2D spectra. The insets in (a) show glucose degradation moieties binding to aluminate-hydrate in grey oilwell cement surfaces through (i) $-\mathrm{COO}^{-}$interactions and (ii) $-\mathrm{COH}$ hydrogen bonds. The corresponding ${ }^{13} \mathrm{C}-{ }^{1} \mathrm{H}$ dipole-dipole interactions observed in the spectra are indicated by red arrows. The symbol “*” indicates a MAS spinning sideband. 
(a)

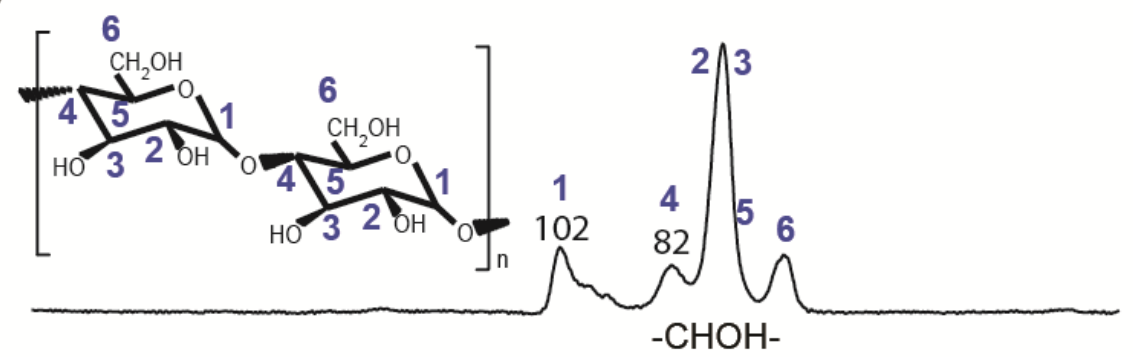

(b)

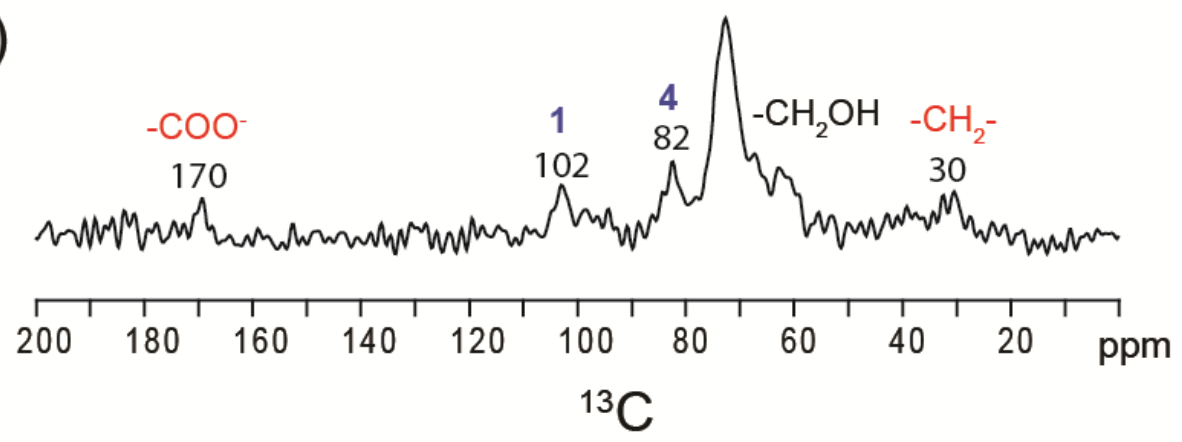

Figure S11. Solid-state $1 \mathrm{D}{ }^{13} \mathrm{C}\left\{{ }^{1} \mathrm{H}\right\}$ CPMAS NMR spectra acquired at $11.7 \mathrm{~T}, 25{ }^{\circ} \mathrm{C}$, and 10 $\mathrm{kHz}$ MAS for (a) maltodextrin and for (b) hydrated tricalcium silicate $\left(4 \mathrm{~h}, 95{ }^{\circ} \mathrm{C}\right)$ initially containing $1 \%$ maltodextrin by weight of tricalcium silicate. Broad resolved ${ }^{13} \mathrm{C}$ signals observed in (a) correspond to distinct ${ }^{13} \mathrm{C}$ species in maltodextrin and are assigned as labeled in the schematic structure. The glycosidic bond that links individual glucose units in maltodextrin is formed by the $C 1$ and $C 4$ carbons that are associated with ${ }^{13} \mathrm{C}$ signals at 102 and $82 \mathrm{ppm}$, respectively. New ${ }^{13} \mathrm{C}$ NMR signals are observed in Figure (b) at approximately 170 and $30 \mathrm{ppm}$ are assigned to $-\mathrm{COO}^{-}$and $-\mathrm{CH}_{2}-$ moieties, respectively, and are likely associated with lower molecular-weight (i.e., $<\mathrm{C}_{6}$ ) saccharinic or other carboxylic acids that form from the alkaline degradation of maltodextrin. Importantly, the spectrum in (b) exhibits ${ }^{13} \mathrm{C}$ signals at 102 and 82 ppm that are characteristic of the $C 1$ and $C 4$ carbon moieties that form the glycosidic linkages in the polysaccharide. This establishes that di- or oligomeric saccharide species are adsorbed on tricalcium silicate surfaces, along with lower molecular-weight alkaline degradation species. 